\title{
Asymmetric Timeliness of Eamings Recognition and Overestimation of Accruals Quality
}

\author{
Wonsun Paek ${ }^{* *}$, Professor, Sungkyunkwan University
}

$\langle$ Abstract

This study examines the relationship between the asymmetric timeliness of earnings recognition and accruals quality. Ball and Shivakumar (2006) provide evidence that the relationship between accruals and cash flows is distorted under the linear assumption. This study estimates new measures of accruals quality after including the asymmetric timeliness of earnings recognition in Dechow and Dichev's (2002) model and compares these with Dechow and Dichev's accruals quality. I decompose Dechow and Dichev's accruals quality into (1) one component after controlling for asymmetric earnings timeliness, which is unexplained by asymmetric timeliness recognition, and (2) another component that is explained incrementally by asymmetric timeliness recognition beyond three consecutive-period operating cash flows. I examine the relationship between decomposed accruals quality and earnings forecast accuracy, cost of debts, and cost of equity. Empirical findings show accruals quality significantly improves after incorporating asymmetric timeliness of earnings recognition. The accruals quality component after incorporating asymmetric timeliness shows significant relationships with earnings forecast accuracy and cost of equity, while the other component does not. This study shows that accruals quality improves when estimated by allowing a non-linear relationship with asymmetric timeliness. This measure enables users to make better decisions when evaluating firms' operating or financing activities.

Keywords: Accruals Quality; Asymmetric Timeliness of Earnings Recognition; Cost of Debts; Cost of Equity; Earnings Forecast Accuracy

JEL Classification: G10, M40

\footnotetext{
* This work was supported by the Ministry of Education of the Republic of Korea and the National Research Foundation of Korea (NRF-2017S1A5A2A01023308).

** Corresponding Author. Address: Business School, Sungkyunkwan University, 25-2, Sungkyunkwan-ro, Jongno-gu, Seoul, Korea 03063; E-mail: wpaek@skku.ac.kr; Tel: +82-2-760-0415.
}

Received: September 17, 2019; Revised: October 28, 2019; Accepted: November 1, 2019 


\title{
차별적 손익인식 적시성과 발생액의 질의 과대추정*
}

백 원 선 (성균관대학교 교수)**

\begin{abstract}
본 연구는 차별적 손익인식 적시성이 발생액의 질에 미치는 영향을 분석하였다. Ball and Shivakumar (2006)는 발생액과 영업현금흐름 간 선형관계 가정이 둘 간 관계를 왜곡한다는 증거를 제시하였다. 본 연구에서는 Dechow and Dichev(2002) 모형에 차별적 손익인식 적시성을 추가하여 발생액의 질을 추정하고, 기존의 발생액의 질과 비교하였다. 발생액의 질을 (1) 차별적 손익인식 적시성이 추가로 설명하는 요소와 (2) 차별적 손익인식 적시성으로 설명되지 않는 요소로 나누고, 각 요소와 이익예측 정확성, 부채조달비용 및 자기자본비용 등의 관계를 분석하였다. 분석결과에 의하면 차별적 손익인식 적시성을 고려했을 때 발생액의 질이 향상되었다. 이익예측정확성 및 자기자본비용과의 관계는 차별적 손익인식 적시성으로 설명되지 않는 요소에서는 유의했지만 차별적 손익인식 적시성이 추가로 설명하는 요소에서는 유의하지 않았다. 본 연구는 발생액의 질의 추정에 차별적 손익인식 적시성을 고려할 때 기존의 발생액의 질의 과대추정오류를 줄일 수 있다는 증거를 제시하였다. 정보이용자는 발생액의 질을 이용한 의사결정을 할 때 차별적 손익인식 적시성을 고려할 필요가 있다는 시사점을 제공하고 있다.
\end{abstract}

핵심 단어 : 발생액의 질, 부채조달비용, 이익예측정확성, 자기자본비용, 차별적 손익인식 적시성

JEL 분류기호: G10, M40

* 이 논문은 2017년 대한민국 교육부와 한국연구재단의 지원을 받아 수행된 연구임 (NRF-2017S1A5A2A01023308).

** 연락담당 저자. 주소: 서울특별시 종로구 성균관로 25-2. 성균관대학교 경영대학. 03063; E-mail: wpaek@skku.ac.kr; Tel: 02-760-0415. 


\section{1. 서론}

본 연구는 영업현금흐름과 발생액 간의 관계를 분석한 Dechow and Dichev(2002) 모형에 차별적 손익인식 적시성을 추가로 고려했을 때 발생액의 질에 미치는 영향을 분석하였다. 차별적 손익인식 적시성(asymmetric timeliness of earnings recognition)은 회계기준의 보수성으로 인하여 손실을 인식할 때보다 이익을 인식할 때에 더 엄격한 요건을 적용하는 것으로 손실은 이익에 비하여 적시성 있게 반영된다는 것을 말한다(Ball and Shivakumar, 2005; Basu, 1997) 한편 이익품질 측정치로 널리 사용되고 있는 발생액의 질(accruals quality)은 발생액과 영업 현금흐름 간 대응의 적절성 정도를 말하는데 전기, 당기 및 차기 영업현금흐름과 관련 없는 당기 유동발생액의 변동성으로 측정되며, 해당 변동성이 클수록 발생액의 질이 낮은 것으로 간주된다(Dechow and Dichev, 2002). 차별적 손익인식 적시성은 보수적 회계처리 때문에 나타나는 현상으로 경영자의 기회주의적 재량권 행사에 따라 발생액의 질에 영향을 미치는 요인과는 질적으로 다르다. 따라서 이를 적절히 통제하지 않은 채 추정한 발생액의 질은 과대추정 가능성이 있으며, 그로 인하여 잘못된 통계적 추론을 초래할 수 있다는 점에서 의미 있는 연구 주제라고 할 수 있다.

Ball and Shivakumar(2006)는 선행연구에서 널리 사용되고 있는 발생액을 종속변수로 하는 모형을 대상으로 발생액과 영업현금흐름 간 선형관계를 가정한 모형의 적합성을 분석하였다. 구체적으로 차별적 손익인식을 추가로 고려한 비선형모형을 추정했을 때 기존 모형보다 발생액과 영업현금흐름의 관계를 더 정확하게 파악할 수 있다는 결과를 보고하였다. 차별적 손익인식 적시성은 회계기준에 내재되어 있는 보수적 특성에 기인하는 것이므로 이를 고려하지 않으면 발생액과 영업현금흐름 간 관계가 왜곡될 수 있다. 즉, 발생액과 영업현금흐름 간 관계가 손실 또는 이익의 경우에 다름에도 불구하고 이를 무시한 채 분석하면 둘 간의 관계를 정확히 추정하기 어렵고, 그로 인해 발생액의 질 측정치에도 측정오차가 포함되는 결과를 초래할 가능성이 있다.

Ball and Shivakumar(2006)는 차별적 손익인식 적시성에 대한 회귀계수의 유의성과 모형의 설명력 향상 여부에 초점을 맞춘 데 반하여 본 연구는 이를 확장하여 Dechow and Dichev(2002) 모형에 차별적 손익인식 적시성을 추가로 고려했을 때 발생액의 질에 어떤 영향을 미치는지를 분석하였다. 이를 위하여 차별적 손익인식 적시성의 고려 여부에 따라 기존의 발생액의 질을 (1) 차별적 손익인식 적시성이 추가로 설명하는 발생액의 질 요소와 (2) 차별적 손익인식 적시성 으로 설명되지 않는 발생액의 질 요소로 구분하였다. 발생액의 질의 역할 또는 유용성을 분석하기 위하여 많은 선행연구에서 살펴본 주요변수들을 식별하여 이들과 발생액의 질 간의 관계를 분석하였다. 분석대상 변수로는 이익예측정확성, 부채조달비용 및 자기자본비용 등을 식별하였다. 먼저 차별적 손익인식 적시성을 통제했을 때 발생액의 질이 향상되는지를 분석하고, 다음에 이들 발생액의 질 요소와 이익예측정확성, 부채조달비용 및 자기자본비용 간의 관계 등이 각 요소에 따라 어떻게 다른지를 살펴보았다.

발생액의 질의 향상여부는 어렵지 않게 예상할 수 있다. Ball and Shivakumar(2006)의 결과를 토대로 추론해 보면 차별적 손익인식 적시성을 고려했을 때 모형의 설명력이 증가하므로 발생액의 
질은 적어도 악화되지는 않을 것으로 예상된다. 발생액의 질은 투자자 또는 채권자에게 기업의 정보위험에 관한 정보를 제공하는 것으로 알려져 있다(Francis et al., 2004). 차별적 손익인식 적시성을 감안한 발생액의 질이 기존의 발생액의 질에 비하여 이익예측정확성, 부채조달비용 또는 자기자본비용 등에 어떠한 차별적 영향을 미칠지는 사전적으로 예측하기 어렵다. 먼저 정보위험의 관점에서는 기존의 발생액의 질에 담겨 있는 정보위험이 차별적 손익인식 적시성의 고려에 따라 구분된 발생액의 질의 두 가지 요소 중 어느 요소와 더 관련 있는지에 달려있다. 두 가지 요소에 반영된 정보위험이 질적으로 다르지 않다면 이들 변수와의 차별적 관계를 보이지 않을 것이고, 질적 차이를 보인다면 차별적 관계를 보일 것으로 예상된다. 또한 과대추정 가능성의 시각에서는 기존의 발생액의 질 중에서 이러한 추정오차를 포함하고 있는 요소가 어느 것인지에 따라 해당 요소와 이익예측정확성, 부채조달비용 또는 자기자본비용 등과의 관계가 달리 나타날 것으로 예상된다.

실증분석은 개별기업 수준이 아닌 연도-산업별 수준에서 수행하였다. 즉, Dechow and $\operatorname{Dichev}$ (2002) 모형을 연도-산업별 횡단면으로 추정하여 발생액의 질을 측정하였고, 다른 변수도 발생액의 질과의 일관성을 유지하기 위하여 연도-산업별 평균으로 계산하였다. 실증분석에 사용한 변수는 선행연구와 일관된 방식으로 측정하였다. 발생액의 질은 Dechow and Dichev (2002) 모형을 사용하였다. 차별적 손익인식 적시성은 악재의 대용치로 (1) Basu(1997)와 같이 음(-)의 주식수익률 또는 (2) Ball and Shivakumar(2005)처럼 음(-)의 영업현금흐름을 이용 하였고, 이들 대용치를 Dechow and Dichev(2002) 모형에 당기 영업현금흐름과의 교차항으로 추가하여 발생액의 질을 추정하였다. 2000년부터 2017년 사이에 한국거래소에 상장된 기업 중 금융업에 속하지 않는 기업을 대상으로 연도-산업별 수준에서 실증분석을 수행하였다.

주요 실증분석 결과를 요약하면 다음과 같다. 첫째, 차별적 손익인식 적시성을 추가로 고려했을 때 발생액의 질은 유의하게 향상되었다. 즉, Dechow and Dichev(2002) 모형의 잔차의 변동성이 유의하게 줄어들었다. 둘째, 선행연구에 따르면 발생액의 질이 높을수록 이익예측정확성이 높아지는데 이러한 관계는 특히 차별적 손익인식 적시성으로 설명되지 않는 발생액의 질 요소에서 유의한 반면에 차별적 손익인식 적시성이 추가로 설명하는 발생액의 질 요소에서는 유의하지 않았다. 셋째, 발생액의 질과 부채조달비용 간 관계는 통상적인 수준에서 유의하지 않았다. 넷째, 발생액의 질과 자기자본비용 간 관계는 차별적 손익인식 적시성으로 설명되지 않는 발생액의 질 요소에서 유의한 반면에 차별적 손익인식 적시성이 추가로 설명하는 발생액의 질 요소에서는 유의하지 않았다.

발생주의 회계의 핵심은 영업현금흐름에 대한 발생액의 시차조정 역할이다. Dechow and $\operatorname{Dichev}(2002)$ 는 이러한 발생액의 역할에 초점을 맞추어 발생액의 질을 제시하였는데 Dechow and Dichev(2002)가 제시한 발생액의 질은 정보위험을 나타내는 측정치로 선행연구에서 널리 사용되고 있다. Ball and Shivakumar(2006)는 차별적 손익인식 적시성을 고려하지 않으면 영업현금흐름의 변동성을 줄여주는 발생액의 역할을 잘못 평가하는 위험을 지적하였지만 그로 인한 발생액의 질에 관한 질적 차별성을 살펴보지는 않았다는 한계를 안고 있다. 본 연구에서는 차별적 손익인식 적시성의 고려에 따른 발생액의 질을 두 가지 요소로 구분하고 각 요소가 
한국증권학회지 제49권 1호 (2020)

정보위험을 어떻게 반영하고 있는지를 분석하였다는 데 그 의의를 찾을 수 있다. 차별적 손익인식 적시성을 구할 때 Basu(1997)처럼 음(-)의 주식수익률을 사용했는지 또는 Ball and Shivakumar (2005)와 같이 음(-)의 영업현금흐름을 사용했는지에 따라 다소 차이는 보였지만 본 연구의 결과는 기존 선행연구에서 분석한 발생액의 질이 차별적 손익인식 적시성을 고려할 때 이익예측정확성과 자기자본비용에 차별적인 영향을 미친다는 것을 보여주고 있다. 이는 기존의 발생액의 질에 반영된 정보위험이 차별적 손익인식 적시성이 추가로 설명하는 발생액의 질 요소보다 차별적 손익인식 적시성으로 설명되지 않는 발생액의 질 요소에 포함되어 있다는 것으로 해석된다. 또한 발생액과 영업현금흐름 간 선형관계 대신에 차별적 손익인식 적시성을 추가로 고려한 비선형관계를 가정했을 때 발생액-영업현금흐름 간 대응 및 발생액의 질의 왜곡을 줄일 수 있고, 그러한 발생액의 질을 더 적절한 이익품질 측정치로 사용할 수 있을 것으로 기대된다. 정보이용자는 발생액의 질을 의사결정에 이용할 때 차별적 손익인식 적시성을 추가로 고려할 필요가 있다는 점을 시사해 준다.

이하 본 연구는 다음과 같이 구성되었다. 제 2 장에서는 연구배경을 소개하고 가설을 예측하였다. 제 3 장에서는 가설을 검증하기 위한 연구 설계를 설명하였다. 제 4장에서는 표본선정과정과 실증분석 결과를 논의하였다. 제 5 장에서 결론을 맺었다.

\section{2. 연구배경 및 가설설정}

발생주의회계에서 발생액은 수익과 비용을 인식하는 과정에서 기간경과에 따른 영업현금 흐름의 일시적 변동을 감소시키고, 감가상각을 통하여 설비자산의 원가배분을 유연하게 함으로써 이익의 안정성과 미래이익예측력을 높이는 역할을 한다(Ball and Shivakumar, 2006). 이에 따라 발생액은 영업현금흐름이 안고 있는 수익과 비용 간 불완전한 대응 및 시차 때문에 야기되는 문제를 완화함으로써 영업현금흐름에 비하여 회계이익의 상대적 정보효과를 높이는 역할을 한다(Dechow, 1994).

Dechow and Dichev(2002)는 이러한 발생액의 역할에 주목하여 발생액의 질 측정치를 제시하였다. 발생주의에서는 영업현금흐름의 일시적 변동을 상쇄하기 위하여 회계연도 말에 수정분개를 하는데 이를 통하여 발생액과 영업현금흐름은 서로 밀접한 관계를 갖게 된다. 그런데 발생액이 영업현금흐름과 관련 없으면 발생액 고유의 역할인 영업현금흐름의 일시적 변동을 감소시키는 역할을 할 수 없게 되며, 그러한 발생액 비중이 클수록 발생액의 질은 저하될 뿐 아니라 이익지속성이 감소하며 시장에서 발생액의 과대평가 경향이 높아진다(Kho and Kim, 2007, 2009; Choi and Paek, 2007). 예를 들어서 전기에 현금으로 먼저 수취한 선수금은 당기에 재화/용역을 제공할 때 수익으로 인식되며, 당기에 외상매출로 발생한 매출채권은 차기에 현금으로 회수된다. 이때 전기 선수금과 당기 매출 또는 당기 매출채권과 차기 현금회수액 간 차이가 클수록 발생액의 질은 저하된다. 이러한 논리에 기초하여 Dechow and Dichev(2002)는 당기 발생액 중에서 전기, 당기 및 차기 영업현금흐름과 상관관계가 없는 발생액의 변동성 (표준편차)을 발생액의 질 측정치로 제안하였다. 발생액의 질은 기업규모, 매출 변동성, 영업현금 
흐름 변동성, 손실빈도 및 영업주기 등 다양한 기업특성변수와 유의한 관계를 보여 다양한 기업특성 및 산업특성을 적절히 반영하는 측정치라는 것이 확인되었다.

Dechow and Dichev(2002) 모형의 설명력과 발생액의 질은 시간의 경과에 따라 지속적으로 감소하고 있다(Bushman et al., 2016; Jung and Paek, 2014).1) 이러한 추세는 영업현금흐름의 시차조정이라는 발생액의 전통적인 역할 외에 손상차손이나 공정가치 평가손익 등과 관련 있는 발생액의 역할과 비중이 점차 커지고 있는 것과 무관하지 않다(Bushman et al., 2016). 발생액의 질이 높을수록 기업가치가 증가하며, 경영성과와 기업가치 간 양 $(+)$ 의 관계가 더 강하게 나타났다(Choi, 2008). 발생액의 질이 높으면 재무분석가는 기업고유의 정보보다 공통정보를 활용하는 경향이 높고, 그에 따라 이익예측정확성이 향상되는 것으로 알려져 있다(Kim et al., 2010). 발생액의 질이 낮으면 감사시간과 감사보수가 유의하게 증가하며, 회계이익의 미래현금 흐름 예측능력이 유의하게 떨어지는 것으로 보고되었다(Kwon and Ki, 2011; Lee, 2012). 또한 발생액의 질은 기업가치의 결정에 중요한 역할을 하는 정보위험을 반영하며, 이러한 정보위험은 정보가 부족한 투자자 입장에서는 분산가능하지 않은 위험에 해당된다. 정보위험이 클수록 투자자는 높은 수준의 자본비용을 요구하게 되는데 선행연구에 따르면 발생액의 질이 낮을수록 자기자본비용 또는 타인자본비용이 증가하는 것으로 보고되었다(Francis et al., 2004, 2005). 반면에 국내기업을 대상으로 한 연구에서는 발생액의 질과 자기자본비용 또는 타인자본비용 간에 유의한 관계를 발견하지 못하였는데 이에 대하여 정보위험의 대용치로서 발생액의 질에 의문을 제기하였다(An et al., 2010).

한편 회계기준에서는 보수적 관점에서 손익을 인식하기 때문에 미실현이익은 미실현손실에 비하여 더 엄격한 인식요건을 적용하도록 되어 있다. 즉, 미실현손실은 가능한 한 신속히 인식하는 반면에 미실현이익은 되도록 천천히 인식하는 요건이 차별적으로 적용된다. Basu(1997)는 이러한 미실현손실과 미실현이익에 대한 차별적 인식요건 때문에 이익과 주식수익률 간 관계가 호재 (good news) 집단과 악재(bad news) 집단 간에 다르다는 결과를 보고하였다.2) 이와 유사하게 Ball and Shivakumar(2005)는 발생액과 영업현금흐름 간 관계가 영업현금흐름이 양(+)인 집단과 음(-)인 집단 간에 다르다는 증거를 제시하였다. Basu(1997)와 Ball and Shivakumar (2005)는 호재 또는 악재의 대용치로 주식수익률의 부호 또는 영업현금흐름의 부호를 사용했다는 차이가 있지만 손익인식 적시성이 차별적이라는 실증증거를 제시하였다는 공통점을 갖는다.

선행연구에 따르면 손익의 차별적 인식에 따른 보수주의는 시간의 경과에 따라 점차 강화되는 추세를 보였으며, 이러한 추세는 다양한 측정치를 이용한 분석에서 일관되게 발견되었다(Givoly

1) 모형의 설명력과 잔차의 변동성과는 역(-)의 관계가 있다. 즉 독립변수가 종속변수의 횡단면 변동성을 잘 설명하면 잔차의 변동성은 감소하게 된다. 다만, 모형의 설명력은 종속변수의 변동성 중에서 독립변수로 설명되는 부분을 비율(\%)로 나타내는 반면에 잔차의 변동성은 종속변수의 변동성 중에서 독립변수로 설명되지 않는 부분을 비율이 아닌 변동성의 크기로 표시한다는 차이가 있다.

2) $\mathrm{Basu}(1997)$ 의 <표 1>에 따르면 호재집단과 악재집단을 구분하지 않은 경우 주식수익률에 대한 순이익의 회귀계수와 모형설명력은 각각 0.113 과 $7.99 \%$ 인 데 반하여 호재집단과 악재집단을 구분한 경우 양 $(+)$ 의 주식수익률과 음(-)의 주식수익률에 대한 순이익의 회귀계수는 각각 0.059 와 0.216 이며, 모형설명력은 $10.09 \%$ 이다. 
한국증권학회지 제49권 1호 (2020)

and Hayn, 2000; Bushman et al., 2016). 보수적 이익은 비보수적 이익에 비하여 이익지속성과 가치관련성이 상대적으로 낮은 것으로 나타났다(Paek and Lee, 2004). 손익인식의 차별성은 이익구성요소 중 발생액은 물론 영업현금흐름에서도 유의하게 관찰되었다. 그러나 영업현금 흐름은 회계기준의 보수주의와 직접적인 관계가 없기 때문에 차별적 손익인식 적시성은 발생액을 이용하여 분석하는 것이 바람직하다고 제안한 연구도 있다(Collins et al., 2014).3)

Ball and Shivakumar(2006)는 발생액과 영업현금흐름 간의 관계를 다룬 기존의 모형들에서 가정하고 있는 발생액과 영업현금흐름 간 선형관계가 실증적으로 타당한지를 검토하였다. 구체적으로 기존의 모형에 손익인식의 차별성을 추가하여 비선형관계를 허용했을 때 손익인식 차별성의 교차항에 대한 회귀계수가 유의하고, 모형의 설명력이 증가하는 등 모형적합성이 향상된다고 보고하였다.4) 이러한 결과를 바탕으로 Ball and Shivakumar(2006)는 손익인식의 차별성을 고려하지 않으면 발생액과 영업현금흐름의 관계를 잘못 파악할 가능성이 있을 뿐 아니라, 이익의 미래현금흐름 예측력을 과소평가할 가능성이 높아진다는 점을 강조하였다.

그러나 Ball and Shivakumar(2006)는 차별적 손익인식이 기존 모형의 적합성을 향상시키는지 여부를 분석하는 것에만 초점을 맞추었을 뿐 차별적 손익인식을 감안한 발생액의 질의 속성 변화에는 주목하지 않았다. 이에 본 연구에서는 Ball and Shivakumar(2006)를 확장하여 손익인식의 차별성을 추가로 고려했을 때 발생액의 질에 어떠한 영향을 미치는지와 손익인식의 차별성을 고려하여 추정한 발생액의 질과 기존의 발생액의 질이 어떠한 차이를 보이는지를 분석하였다. Ball and Shivakumar(2006)의 결과를 토대로 손익인식의 차별성을 추가로 고려할 때 Dechow and Dichev(2002) 모형에서 영업현금흐름과 관련 없는 발생액의 변동성이 작아짐에 따라 발생액의 질이 향상될 것으로 어렵지 않게 예상할 수 있다. 또한 발생액의 질의 경제적 결과를 분석한 선행연구에 따르면 발생액의 질이 높을수록 이익예측정확성이 유의하게 높아지며 (Kim et al., 2010), 자기자본비용과 부채조달비용(타인자본비용)이 유의하게 낮아진다는 결과 (Francis et al., 2004, 2005)와 그렇지 않다는 결과(An et al., 2010)가 혼재되어 있다.

이러한 선행연구 결과를 토대로 본 연구에서는 차별적 손익인식을 추가로 고려하여 추정한 발생액의 질이 차별적 손익인식을 고려하지 않은 기존의 발생액의 질과 어떤 차이를 보이는지를 (1) 발생액의 질과 이익예측정확성, (2) 발생액의 질과 부채조달비용, (3) 발생액의 질과 자기자본 비용 등과의 관계를 중심으로 분석하였다. 이를 위하여 Dechow and Dichev(2002)의 발생액의 질을 차별적 손익인식 적시성이 추가로 설명하는 발생액의 질 요소와 차별적 손익인식 적시성으로

3) Collins et al.(2014)은 영업현금흐름 인식의 차별성은 보수주의보다 기업수명주기단계와 관련이 있다는 증거를 제시하였다.

4) Ball and Shivakumar(2006)가 보고한 결과를 요약하면 다음과 같다. <표 $1>$ 에 보고된 차별적 손익인식을 고려하지 않은 Dechow and Dichev(2002) 모형에서 전기, 당기 및 차기 영업현금흐름의 회귀계수는 각각 $0.22,-0.30,0.12$ 이고 수정설명력은 $7.89 \%$ 이다. <표 $3>$ 에 보고된 차별적 손익인식 적시성을 고려한 Dechow and $\operatorname{Dichev}(2002)$ 모형에서 전기, 당기 및 차기 영업현금흐름의 회귀계수는 각각 $0.22,-0.38,0.14$ 이고, 음(-)의 초과주식수익률과 초과주식수익률 간 교차항(DABNRET× ABNRET) 회귀계수는 0.12 , 수정설명력은 $15.05 \%$ 이다. 이 결과에 대해 Ball and Shivakumar(2006)는 차별적 손익인식 적시성의 추가로 모형적합성이 향상된다고 해석하였다. 
Asymmetric Timeliness of Earnings Recognition and Overestimation of Accruals Quality

설명되지 않는 발생액의 질 요소로 구분하고, 이들 변수와의 관계가 요소별로 어떤 차이를 보이는지를 살펴보았다.

선행연구에 따르면 발생액의 질은 발생액과 영업현금흐름 간 대응이 얼마나 잘 이루어지는지와 관련이 있으며, 특히 영업환경의 불확실성이나 경영자의 기회주의적 재량권 등의 영향을 받는 것으로 알려져 있다(Dechow and Dichev, 2002). 또한 발생액과 영업현금흐름 간 대응이 원활하지 않을수록 이익지속성이 감소하는 것으로 보고되었다(Choi and Paek, 2007). Dechow and $\operatorname{Dichev}$ (2002)는 발생액과 영업현금흐름 간 선형관계를 가정하여 발생액의 질을 측정하였다. 그러나 Ball and Shivakumar(2006)는 보수주의와 관련 있는 차별적 손익인식 적시성 때문에 발생액과 영업현금흐름 간 선형관계 가정에 문제가 있다는 것을 지적하면서 차별적 손익인식 적시성을 고려하지 않으면 발생액과 영업현금흐름 간 대응이 왜곡된다는 결과를 제시하였다. 발생액과 영업현금흐름 간 선형관계 가정으로 양자 간 대응이 왜곡되면 순차적으로 발생액의 질 또한 왜곡 측정되는 결과를 초래한다. 이러한 이유 때문에 차별적 손익인식 적시성을 고려하여 추정된 발생액의 질을 기존의 발생액의 질과 비교하여 그 차이를 밝히는 것은 매우 의미 있는 연구주제라고 할 수 있다.

대부분의 선행연구와 같이 발생액과 영업현금흐름 간 대응을 선형관계로 가정하여 차별적 손익인식 적시성을 고려하지 않은 경우에는 차별적 손익인식 적시성과 관련 있는 발생액이 마치 영업현금흐름과 관계없는 것으로 잘못 분류되어 발생액의 질이 과대추정될 가능성이 높다. 우선 차별적 손익인식 적시성을 추가로 고려함에 따라 이러한 과대추정 가능성이 낮아지는지를 확인하여야 한다. Dechow and Dichev(2002)가 제안한 발생액의 질은 연속된 세기간의 영업 현금흐름으로 설명되지 않는 당기 발생액의 변동성이다. Dechow and Dichev(2002) 모형에 차별적 손익인식 적시성을 추가하여 추정하면 기존의 발생액의 질은 (1) 차별적 손익인식 적시성이 추가로 설명하는 발생액의 질과 (2) 차별적 손익인식 적시성으로 설명되지 않는 발생액의 질로 나눌 수 있다. 차별적 손익인식 적시성의 누락이 발생액의 질에 미치는 영향은 과대추정된다면 차별적 손익인식 적시성이 추가로 설명하는 발생액의 질과 차별적 손익인식 적시성으로 설명되지 않는 발생액의 질로 구분하여 분석함으로써 정확히 확인할 수 있을 것이다.

Ball and Shivakumar(2006)가 보고한 것처럼 Dechow and Dichev(2002) 모형에 차별적 손익인식 적시성을 추가로 고려할 때 모형의 적합도가 높아지는데 본 연구는 차별적 손익인식 적시성의 고려 여부에 따라 발생액의 질이 제공하는 정보위험이 질적으로 변화될 가능성에 주목하였다. 투자자와 채권자가 다양한 정보 관련 변수에 관심을 갖는 이유는 그 변수들이 자신의 의사결정과 관련된 정보위험을 감소시켜 줄 것으로 기대하기 때문이다. 정보위험은 정보의 정확성과 관계가 있는 데 대하여 차별적 손익인식 적시성은 정보의 정확성과 관계가 있을 뿐 아니라, 회계기준에 내재되어 있는 보수주의와도 관련이 있다.

발생액의 질은 선행연구에서 정보위험의 대용치로 널리 사용되고 있는데 발생액의 질이 높으면 자기자본비용이나 부채조달비용은 감소하며, 이익예측정확성은 증가한다. 반면에 차별적 손익인식 적시성과 자기자본비용 간 관계는 유의한 음(-)의 관계를 보인 결과도 있고, 유의하지 않다는 결과도 있는 등 그 결과가 혼재되어 있다(Francis et al., 2004; García Lara et al., 
한국증권학회지 제49권 1호 (2020)

2011). 또한 차별적 손익인식 적시성이 높을수록 이익예측정확성은 떨어진다는 결과가 제시 되었다(Mensah et al., 2004). 이러한 실증결과를 종합해 볼 때 발생액의 질과 차별적 손익인식 적시성이 제공하는 정보위험이 서로 전혀 다르다고 보기 어렵지만 그렇다고 완전히 중복되는 것도 아니라는 추론이 가능하다. 따라서 선행연구에 보고된 발생액의 질과 이익예측정확성, 부채조달비용 및 자기자본비용과의 유의한 관계가 차별적 손익인식 적시성이 추가로 설명하는 발생액의 질 요소와 차별적 손익인식 적시성으로 설명되지 않는 발생액의 질 요소 중 어느 것과 주로 관련 있는지는 사전에 명확히 예측하기 어렵다. 즉, 정보위험이 두 가지 요소 중 어느 것에 주로 포함되어 있는지에 달려있다.

차별적 손익인식 적시성이 추가로 설명하는 발생액의 질이 기존의 발생액의 질에 포함된 정보위험과 질적으로 유사하다면 두 가지 발생액의 질 요소 간에 차이가 없을 것이며, 두 가지 요소를 구분할 필요가 없다. 즉, 두 가지 발생액의 질과 이익예측정확성 또는 자본비용 간의 관계는 질적으로 다르지 않을 것이다. 하지만 정보위험이 두 가지 발생액의 질 요소에 다르게 반영되어 있다면 두 요소와 이익예측정확성, 부채조달비용 및 자기자본비용과의 관계는 차이를 보일 것이다. 동시에 차별적 손익인식 적시성이 누락되면 발생액의 질이 과대추정될 가능성이 있는데 두 가지 요소 중 어느 것에 추정오차가 주로 포함되어 있는지에 따라 두 요소와 이익 예측정확성, 부채조달비용 및 자기자본비용과의 관계가 달라질 것이다. 이러한 논의에 기초하여 다음과 같이 귀무가설의 형태로 연구가설을 설정하였다.

가설: 발생액의 질과 이익예측정확성, 부채조달비용 및 자기자본비용 간의 관계는 차별적 손익인식 적시성이 추가로 설명하는 발생액의 질 요소와 차별적 손익인식 적시성으로 설명되지 않는 발생액의 질 요소 간에 유의한 차이가 없을 것이다.

\section{3. 연구방법}

본 연구의 주된 분석대상인 발생액의 질을 측정하기 위한 Dechow and Dichev(2002) 모형(식 1a)과 이 모형에 차별적 손익인식 적시성을 나타내는 음(-)의 주식수익률 또는 음(-)의 영업현금 흐름을 추가한 모형(식 $1 \mathrm{~b}$ )은 다음과 같다.5)

$$
\begin{aligned}
\text { tac }_{t}= & a_{0}+a_{1} c f_{t-1}+a_{2} c f_{t}+a_{3} c f_{t+1}+e_{1 t} \\
\text { tact }_{t}= & a_{0}+a_{0 \_n e g r e t} \text { negret } t_{t}\left(\text { or } a_{0 \_n e g c f} n e g c f_{t}\right)+a_{1} c f_{t-1}+a_{2} c f_{t} \\
& +a_{2 \_n e g r e t} \text { negret } t\left(\text { or } a_{2 \_n e g c f} \text { neg } c f_{t}\right) \times c f_{t}+a_{3} c f_{t+1}+e_{2 t}
\end{aligned}
$$

변수정의: $\operatorname{tac}_{t}$ 는 $\mathrm{t}$ 년 총발생액, 즉, 현금 외의 유동자산 변화에서 유동성장기부채와 미지급 법인세 외의 유동부채 변화 및 감가상각비와 무형자산상각비를 차감(t년 말과 t-1년

5) Dechow and Dichev(2002)는 종속변수로 운전자본발생액을 사용한 반면에 본 연구에서는 Ball and Shivakumar(2006), Bushman et al.(2016) 등과 같이 총발생액을 사용하였다. 하지만 Dechow and Dichev(2002)와 같이 종속변수로 운전자본발생액을 사용한 경우에도 결과는 질적으로 다르지 않았다. 
말 평균총자산으로 나눔); $c_{t}$ 는 t년 영업현금흐름으로 법인세비용차감전순이익에서 총발생액을 차감(t년 말과 $\mathrm{t}-1$ 년 말 평균총자산으로 나눔); negret $t_{t}$ 는 음(-)의 주식수익률을 나타내는 더미변수, 즉, $t$ 년 주식수익률이 음수이면 1 , 그렇지 않으면 $0 ; n e g c f_{t}$ 는 음(-)의 영업현금흐름을 나타내는 더미변수, 즉, $\mathrm{t}$ 년 영업현금흐름이 음수이면 1, 그렇지 않으면 0.

발생액의 질은 위 식을 연도-산업별 횡단면으로 추정하여 구한 잔차의 연도-산업별 표준편차를 사용하였다. 잔차의 표준편차가 클수록 발생액의 질은 감소한다. 식 (1a)로부터 추정한 잔차 $\left(e_{1 t}\right)$ 의 연도-산업별 표준편차는 Dechow and Dichev(2002)가 제시한 기존의 발생액의 질 $\left(a q_{t}\right)$ 을 나타내는 반면에 식 $(1 \mathrm{~b})$ 로부터 추정한 잔차 $\left(e_{2 t}\right)$ 의 표준편차는 음 $(-)$ 의 주식수익률 $\left(n e g r e t_{t}\right)$ 또는 음(-)의 영업현금흐름 $\left(n e g f_{t}\right)$ 을 경제적 손실의 대용치로 차별적 손익인식 적시성을 통제한 후에 추정한 차별적 손익인식 적시성으로 설명되지 않는 발생액의 질(aq_negret or aq_negcft)을 나타낸다. 이들 발생액의 질 간의 차이에 해당하는 차별적 손익인식 적시성이 추가로 설명하는 발생액의 질(aq_negret_difft or aq_negcf_difft)을 다음과 같이 계산하고, 그 차이가 유의한지를 분석하였다.

$a q \_n e g r e t \_d i f f_{t}\left(a q \_n e g c f_{-} d i f f_{t}\right)=a q_{t}-a q \_n e g r e t_{t}\left(a q \_n e g c f_{t}\right)$

이상의 발생액의 질을 구분한 내용을 정리하면 다음과 같이 표시할 수 있다.

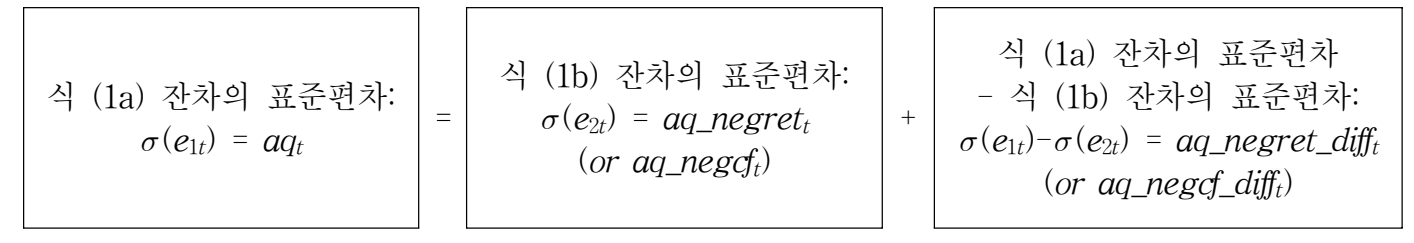

Dechow and Dichev(2002) 모형식 (1a)의 잔차의 표준편차 $\left(\sigma\left(e_{1 t}\right)\right)$ 를 (1) 차별적 손익인식 적시성을 추가한 모형식 (1b)의 잔차의 표준편차 $\left(\sigma\left(e_{2 t}\right)\right)$ 와 (2) 두 가지 표준편차의 차이 $\left(\sigma\left(e_{1 t}\right)\right)-$ $\left(\sigma\left(e_{2 t}\right)\right)$ 인 차별적 손익인식 적시성이 추가로 설명하는 부분으로 나누었다. 만일 차별적 손익인식 적시성을 고려한 후에 추정한 발생액의 질, 즉 차별적 손익인식 적시성으로 설명되지 않는 발생액의 질 $\left(a q \_n e g r e t_{t}\right.$ or $\left.a q \_n e g f_{t}\right)$ 이 기존의 발생액의 질 $\left(a q_{t}\right)$ 보다 향상된다면 둘의 차이에 해당하는 차별적 손익인식 적시성이 추가로 설명하는 발생액의 질(aq_negret_difft or aq_negf_difft)은 유의한 양(+)일 것으로 예상된다.

발생액의 질과 이익예측정확성 간의 관계를 분석하기 위한 모형은 다음과 같다.

$$
\begin{aligned}
& \text { avg_accu_epS } \left.S_{t+1}=k_{0}+k_{1} a q_{t} \text { (or aq_negret } t_{t} \text { or aq_negcf } f_{t}\right) \\
& \left.+k_{2} \text { aq_negret_difft (or aq_negcf_difft }\right)+k_{3} \text { avg_accu_eps } t \\
& +k_{4} \text { std_sale }{ }_{t}+k_{5} \text { std_cf }+k_{6} \text { avg_neg_ibt } t_{t}+k_{7} \text { avg_lasset } t_{t} \\
& +k_{8} \text { avg_levt }+k_{9} \text { avg_lpb }+k_{10} \text { avg_ocycle } e_{t}+w_{2 t}
\end{aligned}
$$


한국증권학회지 제49권 1호 (2020)

변수정의: $a v g \_a c c u \_e p S_{t+1}$ 은 $\mathrm{t}+1$ 년 이익예측정확성, 즉 실제주당순이익과 주당순이익예측 치간 차이의 절대값을 기초주가로 나눈 값의 연도-산업별 평균; $a q_{t}$ 는 식 (1a)로부터 추정된 t년 연도-산업별 발생액의 질; aq_negret $\left(a q \_n e g c f_{t}\right)$ 는 식 (1b)로부터 추정된 t년 음(-)의 주식수익률(영업현금흐름)을 반영한 연도-산업별 발생액의 질; aq_negret_difft $\left(a q \_n e g c f \_d i f f t\right)$ 는 t년 차별적 손익인식 적시성 반영 전후 발생액의 질의 차이, 즉 $a q t-a q \_n e g r e t_{t}\left(a q_{-} n e g\left(f_{t}\right)\right.$; std_salet는 t년 매출변동성, 즉 매출(t년 말과 $\mathrm{t}-1$ 년 말 평균총자산으로 나눔)의 연도-산업별 표준편차; std_c $c_{t}$ 는 $\mathrm{t}$ 년 영업현금흐름변동성, 즉 영업현금흐름(t년 말과 $\mathrm{t}-1$ 년 말 평균총자산으로 나눔)의 연도-산업별 표준편차; $a v g_{-} n e g_{-} i b t_{t}$ 는 t년 손실비중, 즉 연도-산업별 손실보고빈도; avg_lasset $t_{t}$ 는 t년 자산규모, 즉, 자산의 자연대수값의 연도-산업별 평균; $a v g \_l e v_{t}$ 는 t년 부채-자본 비율의 연도-산업별 평균; $a v g_{-} l p b_{t}$ 는 $\mathrm{t}$ 년 주가순자산 비율의 자연대수값의 연도-산업별 평균; $a v g \_o c y c l e t$ 는 t년 영업주기, 즉 매출채권 회수기간과 재고자산 보유기간 합계의 자연대수값의 연도-산업별 평균.

Kim et al.(2011)은 발생액의 질 $\left(a q_{t}\right)$ 과 이익예측정확성 $\left(a v g \_a c c u \_e p S_{t+1}\right)$ 간에 유의한 관계가 있다는 결과를 보고하였다. 본 연구에서는 발생액의 질을 차별적 손익인식 적시성으로 설명되지 않는 발생액의 질 요소 $\left(a q \_n e g r e t_{t}\right.$ or $\left.a q \_n e g f_{t}\right)$ 와 차별적 손익인식 적시성이 추가로 설명하는 발생액의 질 요소(aq_negret_difft or aq_negcf_difft)로 구분했을 때 이익예측정확성과의 관계가 두 가지 요소에서 차별적일 것인지를 분석하였다. 만일 두 가지 발생액의 질 요소의 질적인 차이가 없다면 두 가지 요소와 이익예측정확성 간 관계는 유의하게 다르지 않을 것으로 예상된다. 하지만 두 요소에 반영된 정보위험의 정도가 다르다면 정보위험이 더 많이 반영된 요소에서 이익예측정확성과의 관계가 유의할 것이다.

발생액의 질과 부채조달비용 간의 관계를 분석하기 위한 모형은 다음과 같다.

$a v g \_d e b t \_c o s t_{t}=m_{0}+m_{1} a q_{t}$ (or aq_negret $t_{t}$ or aq_negcf $\left.f_{t}\right)$

$+m_{2}$ aq_negret_difft (or aq_negcf_difft $)+m_{3}$ avg_lev

$+m_{4}$ avg_lasset $t_{t}+m_{5}$ avg_ibt $t_{t}+m_{6}$ avg_lmv $v_{t}+m_{7} s t d \_i b t_{t}$

$+m_{8}$ avg_ocycle $e_{t}+m_{9}$ avg_intcov ${ }_{t}+w_{3 t}$

변수정의: $a v g \_d e b t \_c o s t_{t}$ 는 t년 부채조달비용, 즉 이자비용을 평균이자발생부채의 합계로 나눈 값의 연도-산업별 평균; $a q_{t}$ 는 식 (1a)로부터 추정된 t년 연도-산업별 발생액의 질; $a q \_n e g r e t_{t}\left(a q \_n e g f_{t}\right)$ 는 식 (1b)로부터 추정된 t년 음(-)의 주식수익률(영업 현금흐름)을 반영한 연도-산업별 발생액의 질; aq_negret_diff(taq_negcf_difft)는 $\mathrm{t}$ 년 차별적 손익인식 적시성 반영 전후 발생액의 질의 차이, 즉 aqt-aq_negret $\left(a q \_n e g f_{t}\right) ;$ $a v g_{-} l e v_{t}$ 는 $\mathrm{t}$ 년 부채-자본 비율의 연도-산업별 평균; $a v g_{-}$lasset $_{t}$ 는 $\mathrm{t}$ 년 자산의 자연대수값의 연도-산업별 평균; $a v g \_i b t_{t}$ 는 $\mathrm{t}$ 년 법인세비용차감전순이익(t년 말과 t-1년 말 평균총자산으로 나눔)의 연도-산업별 평균; $a v g \_l m v_{t}$ 는 t년 말 시가총액의 
Asymmetric Timeliness of Earnings Recognition and Overestimation of Accruals Quality

자연대수값의 연도-산업별 평균; std_ibt 는 t년 이익변동성, 즉 법인세비용차감전 순이익(t년 말과 t-1년 말 평균총자산으로 나눔)의 연도-산업별 표준편차; avg_ocycle는 $\mathrm{t}$ 년 영업주기, 즉 매출채권 회수기간과 재고자산 보유기간의 합계의 자연대수값의 연도-산업별 평균; $a v g \_i n t c o v t$ 는 t년 이자보상비율, 즉 이자비용을 영업이익으로 나눈 값의 연도-산업별 평균.

Francis et al.(2005)은 발생액의 질이 낮을수록 부채조달비용이 증가한다는 결과를 보고 하였다. 본 연구에서는 발생액의 질을 차별적 손익인식 적시성으로 설명되지 않는 발생액의 질 요소 $\left(a q \_n e g r e t_{t}\right.$ or $\left.a q \_n e g c f_{t}\right)$ 와 차별적 손익인식 적시성이 추가로 설명하는 발생액의 질 요소(aq_negret_diff or aq_negcf_diff $f_{t}$ 로 구분하고 각 요소가 부채조달비용과 어떤 관계를 갖는지를 분석하였다. 만일 두 가지 발생액의 질 요소에 반영된 정보위험의 질적인 차이가 있다면 이들 요소와 부채조달비용 간 관계는 차별적일 것으로 예상된다.

발생액의 질과 자기자본비용 간의 관계를 분석하기 위한 모형은 다음과 같다.

$$
\begin{aligned}
a v g \_e q t \_c o s t_{t}= & n_{0}+n_{1} \text { aq }\left(\text { or aq_negret } t_{t} \text { or aq_negcf }\right) \\
& +n_{2} \text { aq_negret_difft }(\text { or aq_negcf_diff }) \\
& +n_{3} \text { avg_beta }{ }_{t}+n_{4} \text { avg_lmv }+n_{5} \text { avg_lp } b_{t}+w_{4 t}
\end{aligned}
$$

변수정의: avg_eqt_cost 는 $\mathrm{t}$ 년 자기자본비용, 즉 Botosan and Plumlee(2005)와 같이 t+2년 주당순이익예측치와 $\mathrm{t}+1$ 년 주당순이익예측치의 차이를 $\mathrm{t}$ 년 말 주가로 나눈 값의 제곱근의 연도-산업별 평균; $a q_{t}$ 는 식 (1a)로부터 추정된 t년 연도-산업별 발생액의 질; $a q \_n e g r e t_{t}\left(a q \_n e g c f_{t}\right)$ 는 식 (1b)로부터 추정된 t년 음(-)의 주식수익률(영업 현금흐름)을 반영한 연도-산업별 발생액의 질; aq_negret_difft (aq_negcf_difft)는 t년 차별적 손익인식 적시성 반영 전후 발생액의 질의 차이, 즉 aqt-aq_negret $t_{t}$ $\left(a q n e g c f_{t}\right) ; a v g \_b e t a_{t}$ 는 t년 체계적 위험, 즉 시장모형 $\left(r e t_{t}=g_{0}+g_{1} m k t+r e t_{t}+e_{t}\right)$ 을 연도-산업별로 추정한 $g_{1}$, 단 $r e t_{t}$ 는 t년 주식수익률, rkt_ret $_{t}$ 는 $\mathrm{t}$ 년 시장수익률; $a v g \_l m v_{t}$ 는 $\mathrm{t}$ 년 말 시가총액의 자연대수값의 연도-산업별 평균; $a v g_{-} l p b_{t}$ 는 $\mathrm{t}$ 년 말 주가-순자산 비율의 자연대수값의 연도-산업별 평균.

Francis et al.(2004)은 발생액의 질이 낮을수록 자기자본비용이 증가한다는 결과를 보고 하였다. Francis et al.(2004)은 Value Line에서 제공하는 이익예측치와 주가예측치 등을 이용하여 추정한 자기자본비용을 사용하였다. 그러나 본 연구에서는 변수측정의 복잡성을 피하여 Francis et al.(2004)이 추가분석에서 사용한 Botosan and Plumlee(2005)가 사용한 PEG를 사전적 자기자본비용의 대용치로 사용하였다. 이를 이용하여 발생액의 질을 차별적 손익인식 적시성으로 설명되지 않는 발생액의 질 요소 $\left(a q_{-} n e g r e t_{t}\right.$ or aq_negcf)와 차별적 손익인식 적시성이 추가로 설명하는 발생액의 질 요소(aq_negret_difft or aq_negcf_diff $)$ 로 구분했을 때 어느 요소가 자기자본비용을 더 잘 설명하는지를 분석하였다. 만일 두 가지 발생액의 질 
한국증권학회지 제49권 1호 (2020)

요소가 반영하고 있는 정보위험이 질적으로 다르다면 이들 요소와 자기자본비용 간 관계는 유의하게 다를 것으로 예상된다.

\section{4. 실증분석}

\section{1 표본선정}

본 연구의 표본은 2000년부터 2017년까지 한국거래소에 상장된 기업(KOSPI와 KOSDAQ 포함) 중에서 금융업에 속하지 않은 기업을 대상으로 하였다.6) 실증분석에 사용된 재무자료 중 이익예측정확성, 부채조달비용 및 자기자본비용을 제외한 나머지 변수가 이용가능하지 않은 관측치를 제외하고, 각 변수가 매년 상하위 $1 \%$ 를 벗어나는 극단치를 제거하였다. 또한 발생액의 질의 추정에 필요한 관측치가 산업-연도별(중분류)로 12 개 미만인 경우에는 제외하였다. 이상의 요건을 충족하는 최종표본은 19,027 개 기업-년 또는 444개 산업-년으로 구성되었다. 다만, 이익예측정확성, 부채조달비용 및 자기자본비용은 관측치 수가 최종표본보다 적었는데 이들 변수를 포함한 분석에 사용된 표본 수는 다음과 같다.

(1) 이익예측정확성: 6,839 개 기업-년(428개 산업-년)

(2) 부채조달비용: 16,352 개 기업-년(444개 산업-년)

(3) 자기자본비용: 3,343 개 기업-년(395개 산업-년)

\section{2 기술통계와 상관관계}

<표 1>에 실증분석에 사용된 주요변수의 기술통계를 제시하였다. 차별적 손익인식 적시성을 고려하지 않은 발생액의 질 $\left(a q_{t}\right)$ 의 평균과 중위수는 각각 0.058과 0.056으로 Jung and Paek (2014)에 보고된 것과 크기가 비슷하였다. 음(-)의 주식수익률을 고려하여 추정한 발생액의 질 $\left(a q_{\_} n e g r e t_{t}\right)$ 과 음 $(-)$ 의 영업현금흐름을 고려하여 추정한 발생액의 질 $\left(a q_{-} n e g c f_{t}\right)$ 의 평균 (중위수)은 각각 $0.054(0.052)$ 와 0.054(0.051)이다. 차별적 손익인식 적시성 고려여부에 따른 발생액의 질의 차이는 음(-)의 주식수익률의 경우(aq_negret_diff $f_{t}$ 0.004, 음(-)의 영업현금 흐름의 경우(aq_negcf_difft) 0.004로서 모두 0과 유의하게 다른 것으로 나타났다. 이는 차별적 손익인식 적시성을 고려했을 때 모형 잔차의 변동성(발생액의 질)이 유의하게 작아지며(증가 하며 $)$, 그 변동 폭은 약 $7 \%(=0.004 / 0.058)$ 내외라는 것을 의미한다.

그밖에 이익예측정확성 $\left(a v g \_a c c u \_e p s_{t}\right)$ 의 산업-년 평균과 중위수는 0.097 과 0.052 , 부채 조달비용 $\left(a v g \_d e b t \_c o s t_{t}\right)$ 의 산업-년 평균과 중위수는 0.055 와 0.053 , 그리고 자기자본비용 ( $\left.a v g \_e q t_{-} \cos t_{t}\right)$ 의 산업-년 평균과 중위수는 0.239와 0.196이었다. 특히 부채조달비용과 자기 자본비용의 차이가 매우 컸는데 자기자본제공에 따른 위험과 보상이 상대적으로 더 크다는 것을 말해준다.

6) Dechow and Dichev(2002) 모형을 추정할 때 $t-1$ 년부터 $t+1$ 년까지의 변수가 사용되기 때문에 t년 기준 표본기간은 2000년부터 2017년까지, $t+1$ 년 기준 표본기간은 2001년부터 2018년까지이다. 
Asymmetric Timeliness of Earnings Recognition and Overestimation of Accruals Quality

<표 $1>$ 의 결과는 기존의 발생액의 질에 비하여 차별적 손익인식 적시성을 고려하여 추정한 발생액의 질이 예상대로 유의하게 향상된다는 것을 보여주고 있다.

\section{〈표 1〉 Descriptive Statistics of Main Variables}

This table presents descriptive statistics of main variables. The sample covers 444 non-banking sic-years (based on 19,307 firm-years) listed over Korea Exchange for 2000 2017. aqt is accruals quality for fiscal year $t$, measured as standard deviation of the residuals from the regression of $t_{a c_{t}}=a_{0}+a_{1} c f_{t-1}+a_{2} c f_{t}+a_{3} c f_{t+1}+e_{t}$ by year and two-digit sics, aq_negret $t_{t}$ is accruals quality with negative stock returns for fiscal year $t$, measured as standard deviation of the residuals from the regression of $\operatorname{tac}_{t}=a_{0}+a_{0 \_ \text {negret }}$ negret $t_{t}+a_{1} c f_{t-1}+a_{2} c f_{t}+a_{2 \_ \text {negret }}$ negret $t_{t} \times c f_{t}+a_{3} c f_{t+1}+$ $e_{t}$ by year and two-digit sics, aq_negcf is accruals quality with negative operating cash flows for fiscal year $\mathrm{t}$, measured as standard deviation of the residuals from the regression of $\operatorname{tac}_{t}=$ $a_{0}+a_{0 \_ \text {negc }}$ negret $t_{t}+a_{1} c f_{t-1}+a_{2} c f_{t}+a_{2 \_n e g c f} n e g c f_{t} \times c f_{t}+a_{3} c f_{t+1}+e_{t}$ by year and two-digit sics, aq_ne ${ }^{-}$ gret_difft is difference between accruals quality without and with negative stock returns for fiscal year t, calculated as $a q_{t}-a q_{t} \_n e g r e t, a q \_n e g c f \_d i f f f_{t}$ is difference between accruals quality without and with negative operating cash flows for fiscal year t, calculated as $a q_{t}-a q_{t}$ negcf, avg_accu_epst is forecast accuracy of earnings per share for fiscal year $t$, calculated as the absolute value of actual earnings per share minus six-month consensus forecast of earnings per share, deflated by stock price at the end of fiscal year $\mathrm{t}-1$, avg_debt_cost is after-tax cost of debt for fiscal year $t$, calculated as financing expenses divided by average interest-bearing debts, averaged by year and two-digit sics, and avg_eqt_cost $t_{t}$ is cost of equity for fiscal year t, measured as the square root of forecasted earnings per share for fiscal year $t+2$ minus forecasted earnings per share for fiscal year $\mathrm{t}+1$ over stock price at the end of fiscal year $\mathrm{t}$, averaged by year and two-digit sics, Means in bold are significant at the $1 \%$ level.

\begin{tabular}{lcccccc}
\hline \multicolumn{1}{c}{ Variable } & $\mathrm{n}$ & mean & std & $1 \%$ & median & $99 \%$ \\
\hline aqt & 444 & 0.058 & 0.022 & 0.015 & 0.056 & 0.127 \\
aq_negret & 444 & 0.054 & 0.022 & 0.013 & 0.052 & 0.122 \\
aq_negret_difft & 444 & 0.004 & 0.005 & 0.000 & 0.002 & 0.021 \\
aq_negcf $t$ & 444 & 0.054 & 0.022 & 0.012 & 0.051 & 0.121 \\
aq_negcf_difft & 444 & 0.004 & 0.006 & 0.000 & 0.002 & 0.030 \\
avg_accu_eps $t+1$ & 428 & 0.097 & 0.144 & 0.003 & 0.052 & 0.696 \\
avg_debt_cost $t_{t}$ & 444 & 0.055 & 0.018 & 0.023 & 0.053 & 0.101 \\
avg_eqt_cost & 395 & 0.239 & 0.156 & 0.037 & 0.196 & 0.918 \\
\hline
\end{tabular}

<표 2> panel A에 실증분석에 사용된 주요변수간 Spearman 상관관계를 제시하였다. 차별적 손익인식 적시성을 고려하지 않은 발생액의 질 $\left(a q_{t}\right)$ 과 음 $(-)$ 의 주식수익률을 통제한 후 추정한 발생액의 질 $\left(a q \_n e g r e t_{t}\right)$ 및 음(-)의 영업현금흐름을 통제한 후 추정한 발생액의 질 $\left(a q \_n e g c f_{t}\right)$ 간의 상관관계는 각각 $0.969,0.947,0.940$ 으로 매우 높은 수준을 보였다. 반면에 기존의 발생액의 질과 차별적 손익인식 적시성 고려여부에 따른 발생액의 질의 차이(aq_negret_difft \& aq_negcf _diff $t_{\text {) }}$ 간 상관관계는 0.141 과 0.135 로 낮은 편이다.

발생액의 질과 이익예측정확성, 부채조달비용 및 자기자본비용 간 상관관계는 차별적 손익인식 적시성을 고려했을 때에도 대체로 비슷한 수준을 보였다. 구체적으로 발생액의 질과 이익예측정 확성 간 상관관계는 차별적 손익인식 적시성을 고려했을 때 큰 차이를 보이지 않았다(0.196에서 


\section{〈표 2〉Spearman Correlations between Main Variables}

This table presents Spearman correlation coefficients between main variables in panel A and Spearman correlation coefficients between main variables and firm characteristics in panel B. The sample covers 444 non-banking sic-years (based on 19,307 firm-years) listed over Korea Exchange for 2000 2017. $a q_{t}$ is accruals quality for fiscal year $t$, measured as standard deviation of the residuals from the regression of $t a c_{t}=a_{0}+a_{1} c f_{t-1}+a_{2} c f_{t}+a_{3} c f_{t+1}+e_{t}$ by year and two-digit sics, aq_negret $t_{t}$ is accruals quality with negative stock returns for fiscal year $t$, measured as standard deviation of the residuals from the regression of $t a c_{t}=a_{0}+a_{0 \_ \text {negret }}$ negret $_{t}+a_{1} c f_{\mathrm{t}-1}+$ $a_{2} c f_{t}+a_{2 \_ \text {negret }}$ negret $t_{t} \times c f_{t}+a_{3} c f_{t+1}+e_{t}$ by year and two-digit sics, aq_negcf is accruals quality with negative operating cash flows for fiscal year $t$, measured as standard deviation of the residuals from the regression of $t a c_{t}=a_{0}+a_{0 \_n e g c f}$ negret $t_{t}+a_{1} c f_{t-1}+a_{2} c f_{t}+a_{2 \text { negcf }} n e g c f_{t} \times c f_{t}+a_{3} c f_{t+1}+e_{t}$ by year and two-digit sics, aq_negret_difft is difference between accruals quality without and with

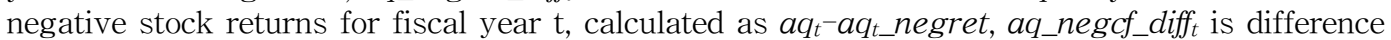
between accruals quality without and with negative operating cash flows for fiscal year $t$, calculated as $a q_{t}-a q_{t} n e g c f$, avg_accu_epst is forecast accuracy of earnings per share for fiscal year $t$, calculated as the absolute value of actual earnings per share minus six-month consensus forecast of earnings per share, deflated by stock price at the end of fiscal year t-1, avg_debt_cost is after-tax cost of debt for fiscal year $t$, calculated as financing expenses divided by average interest-bearing debts, averaged by year and two-digit sics, avg_eqt_cost $t_{t}$ is cost of equity for fiscal year t, measured as the square root of forecasted earnings per share for fiscal year $t+2$ minus forecasted earnings per share for fiscal year $t+1$ over stock price at the end of fiscal year $t$, averaged by year and two-digit sics, std_sale $t$ is sales volatility for fiscal year t, measured as standard deviation of sales by year and two-digit sics, std_cft is operating cash flows volatility for fiscal year $t$, measured as standard deviation of operating cash flows, deflated by average total assets, by year and two-digit sics, avg_neg_ibt $t_{t}$ is frequency of loss for fiscal year $t$, measured as proportion of losses by year and two-digit sics, avg_lasset t $_{t}$ is log of total assets at the end of fiscal year t, averaged by year and two-digit sics, and avg_ocycle $e_{t}$ is income operating cycle for fiscal year t, measured as log of the sum of days accounts receivable and days inventory, averaged by year and two-digit sics. Correlations in bold are significant at the 5\% level.

Panel A: Spearman correlation coefficients between main variables

\begin{tabular}{lccccccc}
\hline \multicolumn{1}{c}{ Variable } & $a q_{t}$ & aq_negret $t$ & $\begin{array}{c}\text { aq_negret } \\
\text { _difft }\end{array}$ & aq_negcft & $\begin{array}{c}\text { aq_negcf } \\
\text { _difft }\end{array}$ & $\begin{array}{c}\text { avg_accu } \\
\text { _epsta1 }\end{array}$ & $\begin{array}{c}\text { avg_debt } \\
\text { _cost } t\end{array}$ \\
\hline aq_negret & 0.969 & & & & & & \\
aq_negret_diff t & 0.141 & -0.055 & & & & & \\
aq_negcft & 0.947 & 0.940 & 0.100 & & & & \\
aq_negcf_difft & 0.135 & 0.093 & 0.113 & -0.078 & & & \\
avg_accu_epSt91 & 0.196 & 0.200 & -0.009 & 0.190 & 0.037 & & \\
avg_debt_cost & 0.341 & 0.330 & 0.061 & 0.299 & 0.158 & 0.173 & \\
avg_eqt_cost $t_{t}$ & 0.249 & 0.241 & 0.044 & 0.241 & 0.059 & 0.274 & 0.361 \\
\hline
\end{tabular}

Panel B: Spearman correlation coefficients between main variables and firm characteristics

\begin{tabular}{lrrrrc}
\hline \multicolumn{1}{c}{ Variable } & $a q_{t}$ & aq_negret $t$ & $\begin{array}{c}\text { aq_negret } \\
\text { _difft }\end{array}$ & aq_negcft & $\begin{array}{c}\text { aq_negcf } \\
\text { _difft }\end{array}$ \\
\hline std_sale $t$ & 0.062 & 0.058 & 0.022 & 0.077 & -0.049 \\
std_cft $_{\text {avg_neg_ibt } t}$ & 0.500 & 0.486 & 0.149 & 0.466 & 0.162 \\
avg_lasset & -0.518 & 0.308 & 0.081 & 0.320 & -0.021 \\
avg_ocycle $_{t}$ & 0.302 & -0.526 & -0.122 & -0.522 & -0.134 \\
\hline
\end{tabular}


Asymmetric Timeliness of Earnings Recognition and Overestimation of Accruals Quality

0.200 또는 0.190 으로). 발생액의 질과 부채조달비용 간 상관관계는 차별적 손익인식 적시성을 고려했을 때 약간 낮아졌지만 큰 차이는 없었다(0.341에서 0.330 또는 0.299로). 마지막으로 발생액의 질과 자기자본비용 간 상관관계 역시 차별적 손익인식 적시성을 고려했을 때 큰 차이를 보이지 않았다(0.249에서 0.241 또는 0.241 로). 반면에 기존의 발생액의 질과 차별적 손익인식 적시성 고려여부에 따른 발생액의 질의 차이(aq_negret_difft \& aq_negcf_difft)와 이익예측 정확성, 부채조달비용 및 자기자본비용 간 상관관계는 매우 약하거나 유의하지 않았다.

<표 2> panel B에 실증분석에 사용된 주요변수와 기업/산업특성 변수 간 Spearman 상관 관계를 보고하였다. 먼저 Dechow and Dichev(2002)와 유사하게 기존의 발생액의 질 $\left(a q_{t}\right)$ 은 매출변동성 $\left(s t d \_s a l e_{t}\right)$ 을 제외한 나머지 기업특성변수와 유의한 상관관계를 나타냈다. 현금흐름 변동성 $\left(s t d \_c f_{t}\right)$ 이 클수록, 손실빈도 $\left(a v g \_n e g_{-} i b t_{t}\right)$ 가 많을수록, 기업규모 $\left(a v g \_l a s s e t_{t}\right)$ 가 작을 수록, 그리고 영업주기 $\left(a v g \_o c y c l e_{t}\right)$ 가 길수록 발생액의 질은 감소하였다. 이러한 발생액의 질 요소와 기업/산업특성 변수 간 상관관계는 주로 차별적 손익인식 적시성으로 설명되지 않는 발생액의 질 요소 $\left(a q \_n e g r e t_{t} \& a q \_n e g c f_{t}\right)$ 에서 두드러진 반면에 차별적 손익인식 적시성이 추가로 설명하는 발생액의 질 요소(aq_negret_difft or aq_negcf_difft)에서는 약하게 유의하거나 또는 유의하지 않았다. 이는 기업/산업특성을 나타내는 정보가 두 요소 간에 질적으로 다르다는 것을 의미한다.

<표 2>의 결과는 차별적 손익인식 적시성 고려여부에 따라 발생액의 질과 이익예측정확성 이나 부채조달비용 또는 자기자본비용 간 상관관계의 속성이 달라진다는 것을 보여주고 있다. 특히 기존의 발생액의 질과 이익예측정확성, 부채조달비용 및 자기자본비용 간 상관관계는 차별적 손익인식 적시성으로 설명되지 않는 발생액의 질 요소(aq_negret $\& a q \_n e g c f_{t}$ )에서 주로 강하게 나타나고 있는 반면에 차별적 손익인식 적시성이 추가로 설명하는 발생액의 질 요소(aq_negret_difft or aq_negcf_difft)에서는 대체로 유의하지 않아 두 요소 간에 질적 차이가 있다는 것을 시사해 준다. 특히 기존의 발생액의 질에 반영된 정보위험의 대부분이 차별적 손익인식 적시성으로 설명되지 않는 발생액의 질 요소(aq_negret \& $\&$ aqneg $\left.f_{t}\right)$ 에 주로 반영되어 있다는 것으로 해석된다.

\section{3 추세분석}

<그림 $1>$ 에는 발생액의 질의 연도별 중위수 추세를 제시하였다. 차별적 손익인식 적시성 고려여부와 관계없이 발생액의 질의 연도별 추세는 유사하였다. 2000년부터 2000년대 후반까지는 눈에 띠는 변화가 보이지 않다가 2000년대 후반 이후 최근까지 다소 감소하는 추세(발생액의 질 향상)를 보이고 있다. 그리고 2000년대에는 차별적 손익인식 적시성의 고려여부에 따른 발생액의 질의 차이가 다른 기간보다 상대적으로 큰 것으로 관찰되었다.

<표 3>에 발생액의 질의 연도별 중위수 $\left(a q_{t}, a q \_n e g r e t_{t}, a q_{-} n e g\left(f_{t}\right)\right.$ 를 종속변수로, 연도 $\left(\right.$ year $\left._{t}\right)$ 를 독립변수로 한 다음의 회귀식 결과를 보고하였다.7)

7) 종속변수에 비해 독립변수가 매우 크기 때문에 회귀계수가 지나치게 작아지는데 이를 조정하기 위하여 추정회귀계수에 100을 곱한 값으로 보고하였다. 


$$
\text { dep. var. }=t_{0}+t_{1} \text { year }+v_{t}
$$

변수정의: dep. var.는 종속변수, 즉 첫 번째 종속변수인 $a q_{t}$ 는 식 (1a)로부터 추정된 $\mathrm{t}$ 년 연도-산업별 발생액의 질, 두 번째 종속변수인 $a q n n e g r e t_{t}$ 는 식 (1b)로부터 추정된 t년 음(-)의 주식수익률을 반영한 연도-산업별 발생액의 질, 세 번째 종속변수인 $a q \_n e g f_{t}$ 는 식 $(1 \mathrm{~b})$ 로부터 추정된 $\mathrm{t}$ 년 음(-)의 영업현금흐름을 반영한 연도-산업별 발생액의 질 $), y e a r_{t}$ 는 표본기간에 속한 연도변수(1983, ..., 2015).

먼저 전반적인 추세를 살펴보면 연도 $\left(\right.$ year $\left._{t}\right)$ 의 회귀계수가 $-0.104 \sim-0.084$ 로 유의한 음(-)으로 나타났다. 이는 표본기간동안 잔차의 표준편차가 유의하게 감소하고 있다는 것이며, 발생액의 질이 유의하게 증가하고 있다는 것을 뜻한다.8) 그런데 <그림 $1>$ 에 제시된 것처럼 2000년대 후반과 2010년대의 추세가 상이하다는 점을 감안하여 표본기간을 (1) 2000년부터 2008년까지 기간과 (2) 2009년부터 2017년까지 기간으로 나누어 회귀식을 추정하였다. <그림 1>의 결과와 유사하게 두 기간의 추세는 일부 다른 양상을 보였다. 특히 2000년부터 2008년까지는 유의하지 않거나 매우 약한 음(-)의 회귀계수가 관찰된 데 반하여 2009년부터 2017년까지는 유의한 음(-)의 회귀계수(-0.154 -0.108)가 관찰되었다.

\section{〈그림 1〉Median Accruals Quality over Time}

This figure shows yearly medians of accruals quality over time. The sample covers 444 non-banking sic-years (based on 19,307 firm-years) listed over Korea Exchange for 2000 2017. $a q_{t}$ is accruals quality for fiscal year $t$, measured as standard deviation of the residuals from the regression of $t a c_{t}=a_{0}+a_{1} c f_{t-1}+a_{2} c f_{t}+a_{3} c f_{t+1}+e_{t}$ by year and two-digit sics, aq_negret $t_{t}$ is accruals quality with negative stock returns for fiscal year $t$, measured as standard deviation of the residuals from the regression of $t a c_{t}=a_{0}+a_{0 \_ \text {negret }}$ negret $t_{t}+a_{1} c f_{t-1}+a_{2} c f_{t}+a_{2 \_ \text {negret }}$ negret $t_{t} \times c f_{t}+a_{3} c f_{t+1}+$ $e_{t}$ by year and two-digit sics, and $a q \_n e g c f_{t}$ is accruals quality with negative operating cash flows for fiscal year $t$, measured as standard deviation of the residuals from the regression of $\operatorname{tac}_{t}=a_{0}+a_{0 \_ \text {negc }}$ negret $t_{t}+a_{1} c f_{t-1}+a_{2} c f_{t}+a_{2 \_ \text {negc }} n e g c f_{t} \times c f_{t}+a_{3} c f_{t+1}+e_{t}$ by year and two-digit sics.

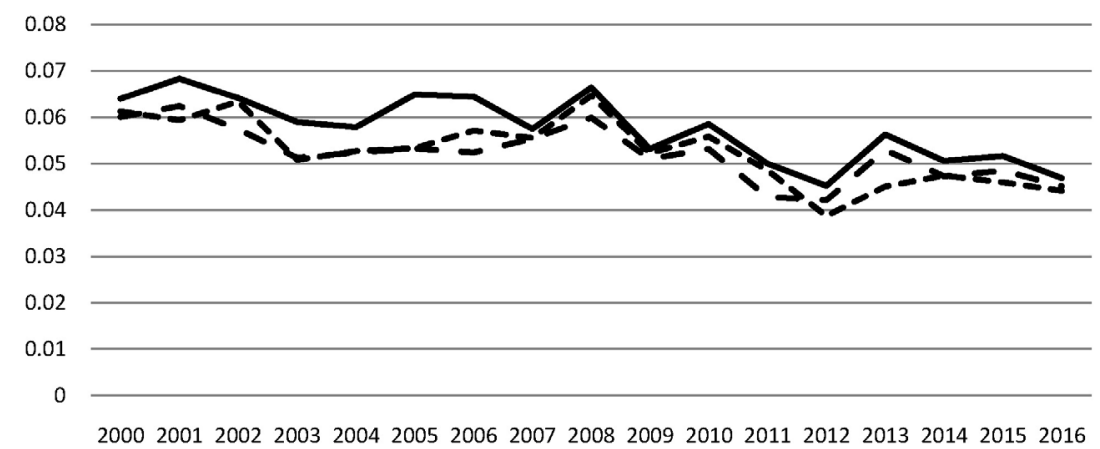

$\longrightarrow a q \quad-0$ aq_negret - - aq_negcf

8) 하지만 본 연구의 표본기간에서 제외된 1980년대와 1990년대에는 2000년대 이후와 달리 발생액의 질이 감소하는 추세를 보였다. 
Asymmetric Timeliness of Earnings Recognition and Overestimation of Accruals Quality

<그림 $1>$ 과 <표 3>의 결과를 요약하면 발생액의 질의 변화추세가 전반적으로 감소하고 있지만 표본기간별로는 상이하다는 것이다. 구체적으로 전반기(2000 2008년)에는 발생액의 질이 크게 변하지 않는 추세를 보인 반면에 후반기(2009 2017년)에는 발생액의 질이 증가하는 추세를 보여 선행연구와 유사한 결과를 나타냈다(Jung and Paek, 2014). 이는 2011년에 이루어진 국제회계기준의 도입과 시기적으로 맞물려 있다고 해석된다.

\section{〈표 3〉 Time Trend Regressions}

This table shows regressions of yearly median accruals quality on year (equation 6). The sample covers 444 non-banking sic-years (based on 19,307 firm-years) listed over Korea Exchange for $2000 \sim 2017 . a q_{t}$ is accruals quality for fiscal year t, measured as standard deviation of the residuals from the regression of $t a c_{t}=a_{0}+a_{1} c f_{t-1}+a_{2} c f_{t}+a_{3} c f_{t+1}+e_{t}$ by year and two-digit sics, aq_negret $t_{t}$ is accruals quality with negative stock returns for fiscal year $t$, measured as standard deviation of the residuals from the regression of tact $=a_{0}+a_{0 \_ \text {negret }}$ negret $t_{t}+a_{1} c f_{t-1}+a_{2} c f_{t}+a_{2 \_n e g r e t}$ negret ${ }_{t} \times c f_{t}+a_{3} c f_{t+1}+e_{t}$ by year and two-digit sics, aq_negcft is accruals quality with negative operating cash flows for fiscal year $t$, measured as standard deviation of the residuals from the regression of $t a c_{t}=a_{0}+a_{0 \_ \text {negcf }}$ negret $t_{t}+a_{1} c f_{t-1}+a_{2} c f_{t}+a_{2 \_ \text {negcf }} n e g c f_{t} \times c f_{t}+a_{3} c f_{t+1}+e_{t}$ by year and two-digit sics, and year $t_{t}$ is year for sample period $(2000, \ldots, 2017)$. ${ }^{a}$ Two-tailed t-test. ${ }^{*},{ }^{* *}$, ${ }^{* * *}$ significant at 10,5 , and $1 \%$ levels, respectively.

dep. var. $=t_{0}+t_{1}$ year $+v_{t}$

(6)

\begin{tabular}{cccc}
\hline \multirow{2}{*}{ Period } & \multicolumn{3}{c}{ dep. var. } \\
\cline { 2 - 4 } & $a q_{t}$ & aq_negret & aq_negcf \\
\hline$t_{1} \times 100(2000 \sim 2017)$ & $-0.104^{* * *}$ & $-0.098^{* * *}$ & $-0.084^{* * *}$ \\
$t_{1} \times 100(2000 \sim 2008)$ & -0.075 & -0.095 & $-0.112^{*}$ \\
$t_{1} \times 100(2009 \sim 2017)$ & $-0.115^{*}$ & $-0.154^{* *}$ & $-0.108^{*}$ \\
\hline
\end{tabular}

\section{4 발생액과 영업현금흐름 간 관계}

<표 4>에는 본 연구의 표본을 대상으로 Dechow and Dichev(2002) 모형을 연도-산업별로 추정하고, 그 평균값을 보고하였다. 다만, Dechow and Dichev(2002)가 종속변수로 사용한 운전자본발생액 대신에 Ball and Shivakumar(2006)와 일관성을 유지하기 위하여 총발생액을 종속변수로 한 분석결과를 보고하였다. 먼저 기본모형에서 $\mathrm{t}$ 년 발생액 $\left(\operatorname{tac}_{t}\right)$ 과 $\mathrm{t}$ 년 영업현금흐름 $\left(c f_{t}\right)$ 간에는 음(-)의 관계(평균 -0.644 , 중위수 -0.643 )가, $\mathrm{t}-1$ 년과 $\mathrm{t}+1$ 년 영업현금흐름 $\left(c f_{t-1} \& c f_{t+1}\right)$ 간에는 양(+)의 관계(각각 평균 0.167 , 중위수 0.164 , 평균 0.238 , 중위수 0.248 )가 관찰되어 선행연구와 일관된 결과를 보였다.

다음으로 음(-)의 주식수익률 $\left(n e g r e t_{t}\right)$ 을 포함한 회귀식에서는 음(-)의 주식수익률과 영업 현금흐름의 교차항 $\left(n e g r e t_{t} \times c f_{t}\right)$ 의 회귀계수(평균 0.025 , 중위수 0.023)가 양 $(+)$ 으로 나타났다. 음(-)의 영업현금흐름 $\left(n e g c f_{t}\right)$ 을 포함한 집단에서는 음(-)의 영업현금흐름과 영업현금흐름 간 교차항 $\left(n e g c f_{t} \times c f_{t}\right)$ 의 회귀계수가 -0.080 로 음(-)의 값을 보여 Ball and Shivakumar(2006)와 질적으로 상이한 결과가 관찰되었다.

Ball and Shivakumar(2006)와 일관되게 차별적 손익인식 적시성을 추가함에 따라 $\mathrm{t}$ 년 
한국증권학회지 제49권 1 호 (2020)

발생액과 t년 영업현금흐름 간 유의한 음(-)의 관계가 더욱 강해진 것을 알 수 있다. 즉, 차별적 손익인식 적시성을 고려하지 않은 경우 $\mathrm{t}$ 년 영업현금흐름 $\left(c f_{t}\right)$ 의 회귀계수는 -0.644 이었는데 차별적 손익인식 적시성을 고려한 경우 $\mathrm{t}$ 년 영업현금흐름 $\left(c f_{t}\right)$ 의 회귀계수는 $-0.684,-0.672$ 로 절대값이 4 6\%만큼 더 커진 것을 알 수 있다. 이는 주식수익률이 양 $(+)$ 인 집단에서 발생액과 영업현금흐름 간 관계가 이론적인 수치인 -1 에 더 가까워진다는 것을 의미한다. 이러한 결과는 모형에 누락되어 있던 변수가 추가될 때 추가변수와 기존의 독립변수 간에 양(+)의 상관관계가 있는 경우 기존 독립변수의 회귀계수가 더 작아진다는 사실에 부합하는 것으로 해석된다(Pindyck and Rubinfeld, 1991).

차별적 손익인식 적시성의 추가로 모형의 설명력은 유의하게 증가했지만 Ball and Shivakumar (2006)와 달리 증가 폭은 크지 않았다. 음(-)의 주식수익률을 이용한 차별적 손익인식 적시성을 고려했을 때 모형의 수정설명력은 $55.8 \%$ 에서 $58.0 \%$ 로 $2.2 \%$ 포인트 증가하였으며, 음(-)의 영업현금흐름을 이용한 차별적 손익인식 적시성을 고려했을 때 모형의 수정설명력은 $55.8 \%$ 에서

\section{〈표 4〉 Estimation of Dechow and Dichev's (2002) Model with Negative Stock Returns or Negative Operating Cash Flows}

This table presents descriptive statistics of cross $^{-}$sectional regression results for Dechow and Dichev model where total accruals are regressed on three consecutive-period operating cash flows (equation 1a) with interaction between current-period operating cash flows and negative stock returns or negative operating cash flows (equation $1 \mathrm{~b}$ ) by year and two-digit SIC codes. The sample covers 444 non-banking sic-years (based on 19,307 non-banking firm-years) listed over Korea Exchange for 2000 2017. tact is total accruals for fiscal year t, measured as changes in current assets other than cash minus current liabilities other than current maturities of long-term liabilities and taxes payable minus depreciation and amortization expenses, deflated by average total assets, $c f_{t}$ is operating cash flows for fiscal year $\mathrm{t}$, measured as income before income tax expenses minus total accruals, deflated by average total assets, negret $t_{t}$ is 1 for negative stock return, and 0 otherwise, and negcf 1 for negative operating cash flows, and 0 otherwise, ${ }^{\mathrm{a}}$ Two-tailed t-test. ${ }^{*},{ }^{* *},{ }^{* * *}$ significant at 10,5 , and $1 \%$ levels, respectively.

$$
\begin{aligned}
\operatorname{tac}_{t}= & a_{0}+a_{1} c f_{t-1}+a_{2} c f_{t}+a_{3} c f_{t+1}+e_{1 t} \\
\text { tac }_{t}= & a_{0}+a_{0 \_ \text {negret }} \text { negret } t_{t}\left(\text { or } a_{0 \_ \text {negcf }} \text { negc } c f_{t}\right)+a_{1} c f t_{-1}+a_{2} c f t \\
& +a_{2 \_ \text {negret }} \text { negret } \\
& \left(\text { or } a_{2 \_n e g c f} \text { neg } c f_{t}\right) \times c f_{t}+a_{3} c f t_{+1}+e_{2 t}
\end{aligned}
$$

\begin{tabular}{|c|c|c|c|c|c|c|c|c|c|}
\hline Variable & mean & std & median & mean & std & median & mean & std & median \\
\hline Intercept & 0.013 & 0.024 & 0.013 & 0.017 & 0.153 & 0.022 & 0.015 & 0.030 & 0.014 \\
\hline negret $_{t}$ & & & & -0.014 & 0.154 & -0.019 & & & \\
\hline$n e g c f_{t}$ & & & & & & & -0.010 & 0.111 & -0.003 \\
\hline$c f_{t-1}$ & 0.167 & 0.167 & 0.164 & 0.162 & 0.160 & 0.156 & 0.166 & 0.156 & 0.157 \\
\hline$c f_{t}$ & -0.644 & 0.189 & -0.643 & -0.684 & 0.609 & -0.685 & -0.672 & 0.282 & -0.676 \\
\hline negret $_{t} \times c f_{t}$ & & & & 0.025 & 0.709 & 0.023 & & & \\
\hline$n e g c f_{t} \times c f_{t}$ & & & & & & & -0.080 & 0.892 & 0.014 \\
\hline$c f_{t+1}$ & 0.238 & 0.185 & 0.248 & 0.228 & 0.189 & 0.239 & 0.239 & 0.187 & 0.245 \\
\hline Adjusted $R^{2}$ & 0.558 & 0.205 & 0.586 & 0.580 & 0.198 & 0.598 & 0.571 & 0.216 & 0.601 \\
\hline $\begin{array}{l}\text { t-test for mean } \\
\text { difference of } \\
\text { adjusted } R^{2} S^{a}\end{array}$ & & & & $0.022^{* * *}$ & & & $0.013^{* * *}$ & & \\
\hline
\end{tabular}


$57.1 \%$ 로 $1.3 \%$ 포인트 증가하는 데 그쳤다.

요약하면 <표 $4>$ 의 결과는 모형의 설명력은 크게 증가하지는 않았지만 발생액과 영업현금흐름 간 관계가 차별적 손익인식 적시성, 즉 주식수익률 또는 영업현금흐름의 부호에 따라 비대칭이라는 Ball and Shivakumar(2006)의 결과를 확인시켜 주고 있다. 이는 차별적 손익인식 적시성을 통제한 후 추정한 발생액의 질의 수준과 특성이 기존의 발생액의 질과 질적으로 차별화될 수 있음을 시사해 준다.

\section{5 발생액의 질과 이익예측정확성}

<표 5>에 이익예측정확성과 발생액의 질 간의 관계를 분석한 결과를 제시하였다. 먼저 발생액의 질을 제외한 분석에서는 주가-순자산 비율 $\left(a v g \_l p b_{t}\right)$ 의 회귀계수가 -0.077 로 $1 \%$ 수준에서 유의하였다. 이는 주가-순자산 비율이 높을수록 이익예측정확성이 높아진다는 것을 뜻한다. 그러나 나머지 통제변수는 유의하지 않았다.

차별적 손익인식 적시성을 고려하지 않은 발생액의 질 $\left(a q_{t}\right)$ 을 포함했을 때 발생액의 질의 회귀계수는 0.854 로 이익예측정확성과 $6.9 \%$ 수준에서 유의한 관계를 보였다. 이는 발생액의 질이 낮을수록 이익예측정확성이 떨어진다는 것으로 선행연구와 일관된 결과이다. 기타 통제변수의 유의성은 앞의 경우와 크게 달라지지 않았다.

차별적 손익인식 적시성을 고려한 발생액의 질을 포함한 분석 중 음(-)의 주식수익률을 통제한 차별적 손익인식 적시성으로 설명되지 않는 발생액의 질 요소(aq_negret $)$ 의 회귀계수는 0.765로 8.3\% 수준에서 유의한 반면에 차별적 손익인식 적시성이 추가로 설명하는 발생액의 질 요소

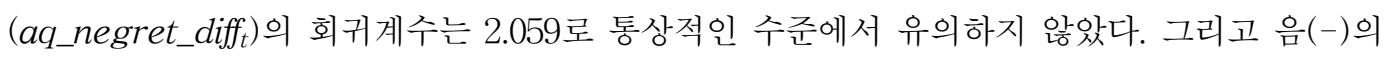
영업현금흐름을 감안하여 추정한 차별적 손익인식 적시성으로 설명되지 않는 발생액의 질 요소 $\left(a q \_n e g\left(f_{t}\right)\right.$ 의 회귀계수는 0.888 로 $6.9 \%$ 수준에서 유의하였고, 차별적 손익인식 적시성이 추가로 설명하는 발생액의 질 요소 $\left(a q \_n e g c f_{-} \operatorname{diff} f_{t}\right)$ 의 회귀계수는 0.211 로 통상적 수준에서 유의하지 않았다. 이는 차별적 손익인식 적시성을 고려함으로써 발생액의 질과 이익예측정확성간 관계를 더 정확히 파악할 수 있다는 의미로 해석된다.

<표 5>의 결과는 차별적 손익인식 적시성 고려 여부와 관계없이 발생액의 질이 낮을수록 이익예측정확성이 대체로 저하되는 것으로 나타났다. 그러나 발생액의 질을 두 요소로 구분한 분석에서는 차별적 손익인식 적시성으로 설명되지 않는 발생액의 질 요소에서만 유의한 관계를 보였다. 이는 차별적 손익인식 적시성을 감안한 발생액의 질을 이용할 때 이익을 더 정확하게 예측할 수 있고, 나머지 요소는 이익예측에 그다지 도움이 되지 않는다는 것을 뜻한다.

\section{6 발생액의 질과 부채조달비용}

<표 6>에 부채조달비용과 발생액의 질 간의 관계를 분석한 결과를 보고하였다. 먼저 발생액의 질을 포함하지 않은 분석에서는 대부분의 통제변수가 유의하였다. 즉, 부채-자본 비율 $\left(a v g \_l e v_{t}\right)$, 자산규모 $\left(a v g \_l a s s e t_{t}\right)$, 이익수준 $\left(a v g_{-} i b t_{t}\right)$, 이익변동성 $\left(s t d \_i b t_{t}\right)$, 이자보상비율 $\left(a v g \_i n t c o v\right) ~$ 등의 회귀계수가 순서대로 각각 $0.005,-0.006,0.090,0.132,0.000$ 으로 $1 \%$ 수준에서 유의하였고 
영업주기(avg_ocycle $)_{t}$ 는 9\% 수준에서 유의한 음(-)으로 나타났다. 즉, 부채-자본 비율이 높거나 이익수준이 높거나 이익변동성이 크거나 이자보상비율이 높을수록 부채조달비용이 증가한 반면에 자산규모가 크거나 영업주기가 길수록 부채조달비용은 감소하여 선행연구와 대체로

\section{〈표 5〉 The Effect of Accruals Quality on Earnings Forecast Accuracy}

This table presents regression results for the effect of accruals quality on earnings forecast accuracy (equation 2). The sample covers 428 non-banking sic-years (based on 6,910 firm-years) listed over Korea Exchange for 2000 2017. avg_accu_epst is forecast accuracy of earnings per share for fiscal year $t$, calculated as the absolute value of actual earnings per share minus six-month consensus forecast of earnings per share, deflated by stock price at the end of fiscal year t-1, $a q_{t}$ is accruals quality for fiscal year $t$, measured as standard deviation of the residuals from the regression of $t a c_{t}=a_{0}+a_{1} c f_{t-1}+a_{2} c f_{t}+a_{3} c f_{t+1}+e_{t}$ by year and two-digit sics, aq_negret $t_{t}$ is accruals quality with negative stock returns for fiscal year $t$, measured as standard deviation of the residuals from the regression of $t a c_{t}=a_{0}+a_{0 \text { negret }}$ negret $t_{t}+a_{1} c f_{t-1}+a_{2} c f_{t}+a_{2}$ negret negret $_{t} \times c f_{t}$ $+a_{3} c f_{t+1}+e_{t}$ by year and two-digit sics, aq_negcft is accruals quality with negative operating cash flows for fiscal year $t$, measured as standard deviation of the residuals from the regression of $\operatorname{tac}_{t}=a_{0}+a_{0 \_ \text {negcf }}$ negret $t_{t}+a_{1} c f_{t-1}+a_{2} c f_{t}+a_{2 \_ \text {negcf }} n e g c f_{t} \times c f_{t}+a_{3} c f_{t+1}+e_{t}$ by year and two-digit sics, aq_negret_difft is difference between accruals quality without and with negative stock returns for fiscal year t, calculated as $a q_{t}-a q_{t}$ negret, aq_negcf_difft is difference between accruals quality without and with negative operating cash flows for fiscal year t, calculated as $a q_{t}-a q_{t} n e g c f$, std_sale $e_{\text {is }}$ sales volatility for fiscal year $t$, measured as standard deviation of sales by year and two-digit sics, std_cft is operating cash flows volatility for fiscal year t, measured as standard deviation of operating cash flows, deflated by average total assets, by year and two-digit sics, $a v g \_n e g_{-} i b t_{t}$ is frequency of loss for fiscal year $\mathrm{t}$, measured as proportion of losses by year and two-digit sics, avg_lasset $t_{t}$ is log of total assets at the end of fiscal year $t$, averaged by year

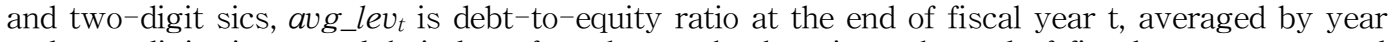
and two-digit sics, $a v g_{-} l p b_{t}$ is log of market-to-book ratio at the end of fiscal year $\mathrm{t}$, averaged by year and two-digit sics, and avg_ocycle $t_{t}$ is income operating cycle for fiscal year t, measured as log of the sum of days accounts receivable and days inventory, averaged by year and two-digit sics. ${ }^{\mathrm{a}}$ Two-tailed t-test.

avg_accu_ep $S_{t+1}=k_{0}+k_{1} a q_{t}$ (or aq_negret $t_{t}$ or aq_negcf $\left.f_{t}\right)$

$+k_{2}$ aq_negret_diff $($ or aq_negcf_diff $t)+k_{3}$ avg_accu_eps

$+k_{4}$ std_sale ${ }_{t}+k_{5}$ std_cft $+k_{6}$ avg_neg_ibt $+k_{7}$ avg_lasset

$+k_{8}$ avg_lev ${ }_{t}+k_{9}$ avg_lph $+k_{10}$ avg_ocycle ${ }_{t}+w_{2 t}$

\begin{tabular}{|c|c|c|c|c|c|c|c|c|c|c|c|c|}
\hline Variable & Coeff. & $t-s t a t^{a}$ & $p$-value & Coeff. & $t^{-} \mathrm{stat}^{a}$ & $p^{\text {-value }}$ & Coeff. & $t^{-}$stat $^{a}$ & $p$-value & Coeff. & $t-s t a t^{a}$ & $p$-value \\
\hline intercept & 0.244 & 0.83 & 0.405 & -0.004 & -0.01 & 0.991 & -0.018 & -0.05 & 0.961 & 0.010 & 0.03 & 0.978 \\
\hline$a q_{t}$ & & & & 0.854 & 1.82 & 0.069 & & & & & & \\
\hline aq_negret $t_{t}$ & & & & & & & 0.765 & 1.74 & 0.083 & & & \\
\hline aq_negret_diff $t$ & & & & & & & 2.059 & 1.09 & 0.275 & & & \\
\hline$a q \_n e g c f_{t}$ & & & & & & & & & & 0.888 & 1.82 & 0.069 \\
\hline aq_negcf_difft & & & & & & & & & & 0.211 & 0.19 & 0.847 \\
\hline avg_accu_eps $t$ & 0.110 & 1.70 & 0.090 & 0.108 & 1.62 & 0.106 & 0.109 & 1.64 & 0.102 & 0.106 & 1.60 & 0.111 \\
\hline std_sale $_{t}$ & -0.049 & -0.97 & 0.331 & -0.064 & -1.25 & 0.213 & -0.059 & -1.18 & 0.240 & -0.067 & -1.25 & 0.213 \\
\hline$s t d \_c f_{t}$ & 0.449 & 1.32 & 0.189 & 0.333 & 1.06 & 0.289 & 0.328 & 1.06 & 0.288 & 0.339 & 1.08 & 0.282 \\
\hline avg_neg_ibt $t_{t}$ & 0.029 & 0.52 & 0.602 & -0.003 & -0.05 & 0.956 & -0.005 & -0.10 & 0.921 & -0.004 & -0.07 & 0.943 \\
\hline avg_lasset $t_{t}$ & -0.008 & -0.71 & 0.477 & 0.001 & 0.05 & 0.958 & 0.001 & 0.10 & 0.917 & 0.000 & 0.00 & 0.997 \\
\hline avg_lev $v_{t}$ & -0.004 & -0.38 & 0.701 & -0.005 & -0.49 & 0.623 & -0.004 & -0.44 & 0.660 & -0.005 & -0.50 & 0.617 \\
\hline$a v g_{-} l p b_{t}$ & -0.077 & -4.80 & $<.0001$ & -0.080 & -4.89 & $<.0001$ & -0.079 & -4.94 & $<.0001$ & -0.081 & -4.84 & $<.0001$ \\
\hline avg_ocyclet & 0.013 & 0.60 & 0.547 & 0.005 & 0.22 & 0.829 & 0.010 & 0.39 & 0.695 & 0.002 & 0.08 & 0.940 \\
\hline Adjusted $R^{2}$ & 0.210 & & & 0.219 & & & 0.219 & & & 0.217 & & \\
\hline
\end{tabular}


Asymmetric Timeliness of Earnings Recognition and Overestimation of Accruals Quality

일관된 결과를 보여주었다.

〈표 6〉 The Effect of Accruals Quality on Cost of Debts

This table presents regression results for the effect of accruals quality on cost of debts (equation 3). The sample covers 444 non-banking sic-years (based on 16,604 firm-years) listed over Korea Exchange for 2000 2017. avg_debt_cost $t_{t}$ is after-tax cost of debt for fiscal year $t$, calculated as financing expenses divided by average interest-bearing debts, averaged by year and two-digit sics, $a q_{t}$ is accruals quality for fiscal year $t$, measured as standard deviation of the residuals from the regression of $t a c_{t}=a_{0}+a_{1} c f_{t-1}+a_{2} c f_{t}+a_{3} c f_{t+1}+e_{t}$ by year and two-digit sics, aq_negret $t_{t}$ is accruals quality with negative stock returns for fiscal year $t$, measured as standard deviation of the residuals from the regression of $t a c_{t}=a_{0}+a_{0 \text { negret }}$ negret $t_{t}+a_{1} c f_{t-1}+a_{2} c f_{t}+a_{2 \_ \text {negret }}$ negret $t_{t} \times c f_{t}$ $+a_{3} c f_{t+1}+e_{t}$ by year and two-digit sics, aq_negcft is accruals quality with negative operating cash flows for fiscal year $t$, measured as standard deviation of the residuals from the regression of $t a c_{t}=a_{0}+a_{0 \_n e g c f}$ negret $t_{t}+a_{1} c f_{t-1}+a_{2} c f_{t}+a_{2 \_n e g c f} n e g c f_{t} \times c f_{t}+a_{3} c f_{t+1}+e_{t}$ by year and two-digit sics, aq_negret_diff $t$ is difference between accruals quality without and with negative stock returns for fiscal year t, calculated as $a q_{t}-a q_{t} \_$negret, aq_negcf_difft is difference between accruals quality without and with negative operating cash flows for fiscal year $\mathrm{t}$, calculated as $a q_{t}-a q_{t} n e g c f$, $a v g_{-} l e v_{t}$ is debt-to-equity ratio at the end of fiscal year $t$, averaged by year and two-digit sics, $a v g_{-} i b t_{t}$ is income before income tax expenses for fiscal year $t$, deflated by average total assets, averaged by year and two-digit sics, std_ibt $t_{t}$ is earnings volatility for fiscal year $\mathrm{t}$, measured as standard deviation of income before income tax expenses by year and two-digit sics, avg_ocycle is income operating cycle for fiscal year $t$, measured as log of the sum of days accounts receivable and days inventory, averaged by year and two-digit sics, and avg_intcov $t$ is interest coverage ratio for fiscal year $t$, calculated as interest expenses divided by operating income, averaged by year and two-digit sics. ${ }^{\mathrm{a}} \mathrm{Tw} \mathrm{w}^{-}$-tailed t-test.

$$
\begin{aligned}
& \left.a v g \_d e b t \_c o s t_{t}=m_{0}+m_{1} a q_{t} \text { (or aq_negret } \text { or }_{\text {a }} \text { anegcf } f_{t}\right) \\
& \left.+m_{2} \text { aq_negret_difft (or aq_negcf_diff } f_{t}\right)+m_{3} \text { avg_lev } \\
& +m_{4} \text { avg_lasset } t_{t}+m_{5} \text { avg_ibt } t_{t}+m_{6} \text { avg_lmv } v_{t}+m_{7} \text { std_ibt } t_{t} \\
& +m_{8} \text { avg_ocycle }{ }_{t}+m_{9} \text { avg_intcov }{ }_{t}+w_{3 t}
\end{aligned}
$$

\begin{tabular}{|c|c|c|c|c|c|c|c|c|c|c|c|c|}
\hline Variable & Coeff. & $t-s t a t^{a}$ & $p$-value & Coeff. & $t^{-}$stat $^{a}$ & $p$-value & Coeff. & $t^{-}$stat $^{a}$ & $p^{\text {-value }}$ & Coeff. & $t^{-}$stat $^{a}$ & $p$-value \\
\hline Intercept & 0.181 & 4.49 & $<.0001$ & 0.178 & 4.45 & $<.0001$ & 0.177 & 4.46 & $<.0001$ & 0.178 & 4.42 & $<.0001$ \\
\hline$a q_{t}$ & & & & 0.117 & 1.61 & 0.108 & & & & & & \\
\hline aq_negret $t_{t}$ & & & & & & & 0.116 & 1.60 & 0.109 & & & \\
\hline aq_negret_difft & & & & & & & 0.140 & 0.80 & 0.423 & & & \\
\hline$a q \_n e g c f_{t}$ & & & & & & & & & & 0.120 & 1.64 & 0.102 \\
\hline aq_negcf_difft & & & & & & & & & & 0.260 & 1.36 & 0.174 \\
\hline avg_levt & 0.005 & 3.38 & 0.001 & 0.005 & 3.37 & 0.001 & 0.005 & 3.36 & 0.001 & 0.005 & 3.37 & 0.001 \\
\hline avg_lasset $t_{t}$ & -0.006 & -3.86 & 0.000 & -0.006 & -3.85 & 0.000 & -0.006 & -3.85 & 0.000 & -0.006 & -3.80 & 0.000 \\
\hline$a v g \_i b t_{t}$ & 0.090 & 2.58 & 0.010 & 0.083 & 2.32 & 0.021 & 0.083 & 2.33 & 0.020 & 0.080 & 2.28 & 0.023 \\
\hline$s t d \_i b t_{t}$ & 0.132 & 3.88 & 0.000 & 0.069 & 1.27 & 0.204 & 0.068 & 1.26 & 0.210 & 0.060 & 1.13 & 0.257 \\
\hline avg_ocycle & -0.004 & -1.70 & 0.090 & -0.005 & -2.02 & 0.044 & -0.005 & -1.94 & 0.052 & -0.005 & -1.84 & 0.066 \\
\hline avg_intcov & 0.000 & 3.61 & 0.000 & 0.000 & 3.47 & 0.001 & 0.000 & 3.45 & 0.001 & 0.000 & 1.72 & 0.086 \\
\hline Adjusted $R^{2}$ & 0.195 & & & 0.199 & & & 0.197 & & & 0.199 & & \\
\hline
\end{tabular}

다음으로 차별적 손익인식 적시성을 고려하지 않은 발생액의 질 $\left(a q_{t}\right)$ 을 포함한 분석에 따르면 발생액의 질의 회귀계수는 0.117 로서 부채조달비용과의 유의수준은 $10.8 \%$ 로 매우 약했다. 차별적 손익인식 적시성을 고려한 발생액의 질을 포함한 분석 중 음(-)의 주식수익률을 이용하여 추정한 
한국증권학회지 제49권 1호 (2020)

차별적 손익인식 적시성으로 설명되지 않는 발생액의 질 요소(aq_negret $)_{t}$ 의 회귀계수는 0.116, 차별적 손익인식 적시성이 추가로 설명하는 발생액의 질 요소(aq_negret_diff $t$ 의 회귀계수는 0.140 으로 통상적인 수준에서 유의하지 않았다. 그리고 음(-)의 영업현금흐름을 이용하여 추정한 차별적 손익인식 적시성으로 설명되지 않는 발생액의 질 요소 $\left(a q \_n e g c f_{t}\right)$ 의 회귀계수는 0.120 , 차별적 손익인식 적시성이 추가로 설명하는 발생액의 질 요소 $\left(a q \_n e g c f \_d i f f t\right)$ 의 회귀계수는 0.260 으로 둘 다 통상적인 수준에서 유의하지 않았다.

<표 6>의 결과에 따르면 발생액의 질과 부채조달비용 간 관계는 유의수준 $10 \%$ 안팎으로 매우 약했다.

\section{7 발생액의 질과 자기자본비용}

<표 7>에 자기자본비용과 발생액의 질 간의 관계를 분석한 결과를 보고하였다. 먼저 발생액의

\section{〈표 7〉 The Effect of Accruals Quality on Cost of Equity}

This table presents regression results for the effect of accruals quality on cost of equity (equation 4). The sample covers 395 non-banking sic-years (based on 3,365 firm-years) listed over Korea Exchange for 2000 2017. avg_eqt_cost is cost of equity for fiscal year t, measured as the square root of forecasted earnings per share for fiscal year $t+2$ minus forecasted earnings per share for fiscal year $t+1$ over stock price at the end of fiscal year $t$, averaged by year and two-digit sics, $a q_{t}$ is accruals quality for fiscal year $t$, measured as standard deviation of the residuals from the regression of $t a c_{t}=a_{0}+a_{1} c f_{t-1}+a_{2} c f_{t}+a_{3} c f_{t+1}+e_{t}$ by year and two-digit sics, aq_negret $t_{t}$ is accruals quality with negative stock returns for fiscal year $t$, measured as standard deviation of the residuals from the regression of $t a c_{t}=a_{0}+a_{0 \_ \text {negret }}$ negret $t_{t}+a_{1} c f_{t-1}+a_{2} c f_{t}+a_{2}$ negret negret $t_{t} \times c f_{t}$ $+a_{3} c f_{t+1}+e_{t}$ by year and two-digit sics, aq_negcft is accruals quality with negative operating cash flows for fiscal year $t$, measured as standard deviation of the residuals from the regression of $\operatorname{tac}_{t}=a_{0}+a_{0 \text { negcf }}$ negret $t_{t}+a_{1} c f_{t-1}+a_{2} c f_{t}+a_{2 \text { negcf }} n e g c f_{t} \times c f_{t}+a_{3} c f_{t+1}+e_{t}$ by year and two-digit sics, aq_negret_diff $t$ is difference between accruals quality without and with negative stock returns for fiscal year $\mathrm{t}$, calculated as $a q_{t}-a q_{t}$ negret, $a q_{n}$ negcf_diff $t$ is difference between accruals quality without and with negative operating cash flows for fiscal year t, calculated as $a q_{t}-a q_{t} n e g c f$,

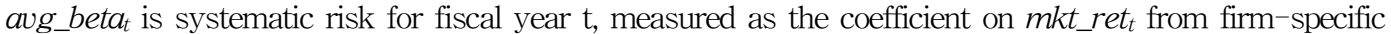
regressions of ret $t_{t}=g_{0}+g_{1}$ mkt_ret $_{t}+e_{t}$ where $m k t \_r e t_{t}$ is market returns for fiscal year $\mathrm{t}$, averaged by year and two-digit sics, $a v g_{-} l m v_{t}$ is $\log$ of equity market value at the end of fiscal year $t$, averaged by year and two-digit sics, and $a v g_{-} l p b_{t}$ is $\log$ of market-to-book ratio at the end of fiscal year $t$, averaged by year and two-digit sics. ${ }^{\mathrm{a}}$ Two-tailed $\mathrm{t}$-test.

$$
\begin{aligned}
& \text { avg_eqt_cost } \left.t_{t}=n_{0}+n_{1} a q_{t} \text { (or aq_negret } \text { or }_{\text {a }} \text { aq_negcf } f_{t}\right) \\
& \left.+n_{2} \text { aq_negret_difft (or aq_negcf_diff }\right) \\
& +n_{3} \text { avg_beta }{ }_{t}+n_{4} \text { avg_lmv } v_{t}+n_{5} \text { avg_lpb } b_{t}+w_{4 t}
\end{aligned}
$$

\begin{tabular}{|c|c|c|c|c|c|c|c|c|c|c|c|c|}
\hline Variable & Coeff. & $t^{-}-\mathrm{stat}^{a}$ & $p^{\text {-value }}$ & Coeff. & $t^{-}$stat $^{a}$ & $p^{\text {-value }}$ & Coeff. & $t^{-}$stat $^{a}$ & $p_{\text {-value }}$ & Coeff. & $t^{-}$stat ${ }^{a}$ & $p^{-v a l u e}$ \\
\hline Intercept & 1.167 & 4.25 & $<.0001$ & 0.346 & 1.27 & 0.204 & 0.338 & 1.24 & 0.214 & 0.363 & 1.35 & 0.177 \\
\hline$a q_{t}$ & & & & 1.898 & 4.60 & $<.0001$ & & & & & & \\
\hline aq_negret $t_{t}$ & & & & & & & 1.796 & 4.47 & $<.0001$ & & & \\
\hline aq_negret_difft & & & & & & & 3.409 & 1.86 & 0.063 & & & \\
\hline$a q \_n e g c f_{t}$ & & & & & & & & & & 1.943 & 4.87 & $<.0001$ \\
\hline aq_negcf_difft & & & & & & & & & & 0.863 & 0.55 & 0.582 \\
\hline avg_betat & 0.107 & 2.48 & 0.014 & 0.062 & 1.32 & 0.186 & 0.065 & 1.40 & 0.163 & 0.059 & 1.30 & 0.195 \\
\hline$a v g_{-} l m v_{t}$ & -0.041 & -4.19 & $<.0001$ & -0.012 & -1.21 & 0.227 & -0.012 & -1.20 & 0.232 & -0.012 & -1.28 & 0.202 \\
\hline$a v g \_l p b_{t}$ & -0.090 & -4.68 & $<.0001$ & -0.129 & -7.06 & $<.0001$ & -0.130 & -6.98 & $<.0001$ & -0.128 & -7.11 & $<.0001$ \\
\hline Adjusted $R^{2}$ & 0.278 & & & 0.322 & & & 0.323 & & & 0.322 & & \\
\hline
\end{tabular}


Asymmetric Timeliness of Earnings Recognition and Overestimation of Accruals Quality

질을 제외한 분석에서는 체계적 위험 $\left(\operatorname{beta}_{t}\right)$ 과 시가총액 $\left(a v g \_l m v_{t}\right)$ 및 주가-순자산 비율 $\left(a v g \_l p b_{t}\right)$ 등의 회귀계수가 각각 $0.107,-0.041,-0.090$ 으로 모두 유의하였다. 이는 체계적 위험이 높거나 시가총액이 작을수록, 그리고 주가-순자산 비율이 낮을수록 자기자본비용이 커졌다는 것으로 선행연구의 결과와 대체로 일치한다.

차별적 손익인식 적시성을 고려하지 않은 발생액의 질 $\left(a q_{t}\right)$ 을 포함했을 때 발생액의 질의 회귀계수는 1.898 로 자기자본비용과 유의한 관계를 보였다. 즉, 발생액의 질이 낮을수록 자기자본비용이 커진다는 선행연구와 일관된 결과를 보여주었다. 다만, 통제변수 중에서 체계적 위험과 시가총액의 유의성이 사라지고, 주가-순자산 비율만이 유의한 음(-)의 회귀계수를 보였다.

차별적 손익인식 적시성을 고려한 발생액의 질을 포함한 분석 중 음(-)의 주식수익률을 통제한 차별적 손익인식 적시성으로 설명되지 않는 발생액의 질 요소(aq_negret $t_{t}$ 의 회귀계수는 1.796 으로 $1 \%$ 미만의 수준에서 유의하였고, 차별적 손익인식 적시성이 추가로 설명하는 발생액의 질 요소 $\left(a q \_n e g r e t \_d i f f_{t}\right)$ 의 회귀계수는 3.409로 6.3\% 수준에서 약하게 유의하였다. 그리고 음(-)의 영업현금흐름을 감안하여 추정한 차별적 손익인식 적시성으로 설명되지 않는 발생액의 질 요소 $\left(a q \_n e g\left(f_{t}\right)\right.$ 의 회귀계수는 1.943 으로 $1 \%$ 미만의 수준에서 유의하였고, 차별적 손익인식 적시성이 추가로 설명하는 발생액의 질 요소 $\left(a q \_n e g c f \_d i f f_{t}\right)$ 의 회귀계수는 0.863 으로 통상적 수준에서 유의하지 않았다.

$<$ 표 7>의 결과는 차별적 손익인식 적시성 고려 여부와 관계없이 발생액의 질이 낮을수록 자기자본비용이 증가하는 것으로 나타났다. 특히 발생액의 질과 자기자본비용 간 유의한 관계는 차별적 손익인식 적시성으로 설명되지 않는 발생액의 질 요소 $\left(a q \_n e g r e t_{t} \& a q \_n e g c f_{t}\right)$ 에서만 유의하였고 차별적 손익인식 적시성이 추가로 설명하는 요소(aq_negret_difft \& aq_negcf_difft) 에서는 유의하지 않거나 매우 약했다. 이는 차별적 손익인식 적시성의 통제 여부가 자기자본 비용과의 관계에서 중요한 역할을 하는 것을 뜻한다.

\section{5. 결론}

본 연구에서는 Dechow and Dichev(2002) 모형에 차별적 손익인식 적시성을 통제하여 추정한 발생액의 질과 기존의 발생액의 질을 비교하였다. 대부분의 선행연구에서 발생액과 영업현금흐름 간 선형관계를 가정하고 분석을 수행하였다. 그런데 이러한 선형관계 가정은 발생액과 영업 현금흐름 간 관계를 왜곡할 수 있다는 문제를 야기한다. Ball and Shivakumar(2006)는 비선형 관계를 허용했을 때 모형의 설명력과 적합성이 향상된다는 증거를 제시하였다.

본 연구에서는 Dechow and $\operatorname{Dichev}(2002)$ 모형에 차별적 손익인식 적시성을 나타내는 음(-)의 주식수익률 또는 음(-)의 영업현금흐름과 당기 영업현금흐름의 교차항을 추가하여 발생액의 질을 추정하고, 기존의 발생액의 질과 비교하였다. 발생액의 질을 분석한 선행연구에 의하면 발생액의 질과 이익예측정확성, 부채조달비용 및 자기자본비용 간에 유의한 관계가 있다고 알려져 있다. 본 연구에서는 기존의 발생액의 질을 (1) 차별적 손익인식 적시성으로 설명되지 않는 발생액의 질과 (2) 차별적 손익인식 적시성이 추가로 설명하는 발생액의 질로 구분하고 
한국증권학회지 제49권 1호 (2020)

이들 요소와 이익예측정확성, 부채조달비용 및 자기자본비용간의 관계를 분석하였다. 만일 차별적 손익인식 적시성 반영에 따른 두 가지 발생액의 질 요소가 질적으로 다른 속성을 갖는다면 이익예측정확성, 부채조달비용 및 자기자본비용과의 유의한 관계는 두 가지 요소에서 다르게 나타날 것으로 예상된다.

주요 실증분석 결과에 따르면 차별적 손익인식 적시성으로 설명되지 않는 발생액의 질이 기존의 발생액의 질보다 유의하게 향상되었다. 발생액의 질과 이익예측정확성 및 자기자본비용 간 유의한 관계는 주로 차별적 손익인식 적시성으로 설명되지 않는 발생액의 질 요소에서 일관되게 관찰되었다. 다만, 발생액의 질과 부채조달비용 간의 관계는 매우 약하여 통상적인 수준에서 유의하지 않았다.

본 연구는 Ball and Shivakumar(2006)의 결과를 확장하여 차별적 손익인식 적시성을 고려한 발생액의 질이 기존의 발생액의 질에 비하여 이익예측정확성 및 자기자본비용 등과 더 유의한 관계를 갖는 측정치라는 증거를 제시하였다. 특히 기존의 발생액의 질 중에서 차별적 손익인식 적시성이 추가로 설명하는 발생액의 질보다는 차별적 손익인식 적시성으로 설명되지 않는 발생액의 질에서 유의한 관계가 두드러지게 관찰되었다. 이러한 결과는 발생액-영업현금흐름의 대응관계를 선형관계로 볼 것인지, 아니면 비선형관계로 볼 것인지에 따라 발생액-영업현금 흐름의 대응관계와 발생액의 질이 달라질 수 있다는 선행연구의 논리와 결과에 기초한 증거로서 발생액의 질을 의사결정의 수단으로 사용하는 정보이용자에게 차별적 손익인식 적시성을 추가로 고려할 필요가 있다는 시사점을 제공했다는 데 본 연구의 공헌점을 찾을 수 있다. 
Asymmetric Timeliness of Earnings Recognition and Overestimation of Accruals Quality

\section{References}

An, Y., J. Kim, and D. Kim, 2010, Is Accounting Information Quality Priced in the Korean Markets? Korean Journal of Financial Studies, Vol. 39 (1), pp. 133-159.

Ball, R., and L. Shivakumar, 2005, Earnings Quality in UK Private Firms: Comparative Loss Recognition Timeliness, Journal of Accounting and Economics, Vol. 39 (1), pp. 83-128.

Ball, R., and L. Shivakumar, 2006, The Role of Accruals in Asymmetrically Timely Gain and Loss Recognition, Journal of Accounting Research, Vol. 44 (2), pp. 207-242.

Basu, S., 1997, The Conservatism Principle and the Asymmetric Timeliness of Earnings, Journal of Accounting and Economics, Vol. 24 (1), pp. 3-37.

Botosan, C. and M. Plumlee, 2005, Assessing Alternatives Proxies for the Expected Risk Premium, The Accounting Review, Vol. 80 (1), pp. 21-53.

Bushman, R., A. Lerman, and X. Zhang, 2016, The Changing Landscape of Accrual Accounting, Journal of Accounting Research, Vol. 54 (1), pp. 42-77.

Choi, J., 2008, An Empirical Study on the Relationship between Earnings Quality and Firm Value, Asia-Pacific Journal of Financial Studies, Vol. 37 (5), pp. 813-839.

Choi, K., and W. Paek, 2007, Accrual Quality Based on Convertibility into Cash and Accrual Anomaly, Korean Accounting Review, Vol. 32 (3), pp. 1-26.

Collins, D., P. Hribar, and X. Tian, 2014, Cash Flow Asymmetry: Cause and Implications for Conditional Conservatism Research, Journal of Accounting and Economics, Vol. 58 (2-3), pp. 173-200.

Dechow, P., 1994, Accounting Earnings and Cash Flows as Measures of Firm Performance: The Role of Accounting Accruals, Journal of Accounting and Economics, Vol. 18 (1), pp. $3-42$.

Dechow, P., and I. Dichev, 2002, The Quality of Accruals and Earnings: The Role of Accrual Estimation Errors, The Accounting Review, Vol. 77 (Supplement), pp. 35-59.

Francis, J., R. Lafond, P. Olsson, and K. Schipper, 2004, Cost of Equity and Earnings Attributes, The Accounting Review, Vol. 79 (4), pp. 967-1010.

Francis, J., R. Lafond, P. Olsson, and K. Schipper, 2005, The Market Pricing of Accruals Quality, Journal of Accounting and Economics, Vol. 39 (2), pp. 295-327.

García Lara, J., B. García Osma, and F. Penalva, 2011, Conditional Conservatism and Cost of Capital, Review of Accounting Studies, Vol. 16 (2), pp. 247-271.

Givoly, D., and C. Hayn, 2000, The Changing Time-Series Properties of Earnings, Cashflows and Accruals: Has Financial Reporting Become More Conservative? Journal of Accounting and Economics, Vol. 29 (3), pp. 287-320. 
한국증권학회지 제49권 1호 (2020)

Jung, J., and W. Paek, 2014, Trend of Earnings Quality, Korean Accounting Journal, Vol. 23 (4), pp. 1-42.

Kho, B.-C., and J.-W. Kim, 2007, Does the Accrual Anomaly Reflect a Risk Factor? The Case of the Korean Stock Market, Asia-Pacific Journal of Financial Studies, Vol. 36 (3), pp. 425-461.

Kho, B.-C., and J.-W. Kim, 2009, Accrual Anomaly and Arbitrage Trading Opportunity, Korean Journal of Financial Studies, Vol. 38 (1), pp. 77-105.

Kim. J., H. Paik, and J. Goh, 2010, The Effect of Accrual Quality and Analysts' Information Environments on Analysts' Forecast Accuracy, Korean Accounting Review, Vol. 35 (3), pp. 1-35.

Kwon, S. Y., and E. S. Ki, 2011, The Effect of Accruals Quality on the Audit Hour and Audit Fee, Korean Accounting Review, Vol. 36 (4), pp. 95-137.

Lee, S. Y., 2012, Accruals Quality and the Ability of Earnings to Predict Future Cash Flows, Korean Accounting Journal, Vol. 21 (6), pp. 349-378.

Mensah, Y., X. Song, and S. Ho, 2004, The Effect of Conservatism on Analysts' Annual Earnings Forecast Accuracy and Dispersion, Journal of Accounting, Auditing \& Finance, Vol. 19 (2), pp. 159-183.

Paek, W., and S. Lee, 2004, Conservatism, Earnings Persistence and Equity Valuation, Korean Accounting Review, Vol. 29 (1), pp. 1-27.

Pindyck, R., and D. Rubinfeld, Econometric Models and Economic Forecasts, $3^{\text {rd }}$ ed., McGraw-Hill, New York, 1991. 